\title{
Cooperation Against Theft: A Test of Incentives for Water
}

\section{Management in Tunisia}

August 23, 2013

\begin{abstract}
Theft of water by manipulating meters constrains economic pricing in semi-arid regions. Cooperative management can reduce theft, improving incentives for efficient water use, by inducing peer monitoring. We show in a theoretical model that theft is more likely when prices are high, punishments weak and cooperatives large. We show how cooperative membership and punishment levels are determined endogenously by constraints on monitoring. We test the model on data from Tunisia, relying on instruments that proxy for unobservable monitoring costs. The results confirm that well-designed incentives can reduce theft, and that constraints on monitoring costs affect institutional design.
\end{abstract}

JEL classification: D82, Q13, Q15, Q25

Keywords: Cooperatives; Cooperative size; Irrigation; Joint responsibility; Peer monitoring; Tunisia; Water theft. 
Economic behavior is influenced not only by formal incentives but also by institutions, which can be understood as informal systems of rules, enforced by a variety of explicit or implicit means. However, institutions themselves evolve in part because of their incentive properties - certain institutions are more suited for some economic environments than others. For instance, many institutions are formed in response to a perceived collective action problem, which the effective design of such institutions can help to alleviate, though rarely without some cost. In this paper we look at the influence of institutions on a serious problem that arises in water management, namely the problem of water theft. The growing scarcity of fresh water in many parts of the world and especially in the agricultural sector has led to an urgent search for solutions, including the adoption of economic pricing policies to encourage conservation (see Johansson 2002, for a review). But it is becoming apparent that when farmers are in a position to steal water, typically by manipulation of water meters $^{1}$, pricing policies may not only fail to encourage conservation, but they may even increase the incidence of theft itself. In the presence of theft, optimal pricing rules need to be adjusted and prices will typically be lower than in its absence (see section B.1 in the Appendix for full details): it is worth tolerating some allocative inefficiency in water use in return for a lower incidence of theft.

Theft does not take place in an institutional vacuum; indeed, different types of water institutions may create more or less favorable conditions for theft to flourish. In particular, it is well known that cooperative institutions may be well suited to deal with a number of collective action problems that arise in water management, though their success in doing so depends on some quite precise features of their design. In this article we show that such institutions may also be well suited to dealing with theft; we discuss the features of their design that enable them to do so using both theory and empirical evidence. We show that the incidence of theft varies considerably in response to these features and discuss implications for policy. We consider in particular the properties of water 
users' associations whose members are subject to joint responsibility for aggregate quantities of water used, and show that this feature is likely to induce peer-monitoring by cooperative members, which might be a more efficient means of reducing theft than any available to more centralized management structures.

Many government authorities are reluctant to acknowledge the severity of the problem of water theft, and it is frequently claimed that the authorities' inability to recover costs of water supply from users is due to purely technical difficulties such as leakages from the water supply network. Two kinds of evidence from our own research make us think this is an implausible explanation: first, and on an anecdotal level, many farmers can be observed using water in ways that seem inconsistent with their facing full economic prices (placing rotating sprays at the corners of fields where only a quarter of the emitted water falls on the land being irrigated, for example). Secondly, the econometric analysis we perform below and the pricing policy practised in Tunisia indicate that it is unlikely that technical explanations can account for most of the discrepancy, because our results show that the discrepancy is related to economic rather than purely physical variables in a way that theft can account for better than leakage. It is not so much that people respond to prices, whereas pipes do not; the maintenance of pipes could, after all, both respond to economic incentives and affect rates of leakage. So it is more that theft might respond to prices in a different way from maintenance: higher prices would be expected to increase incentives for theft but to diminish leakage via incentives for improved maintenance. It might also be the case that higher rates of leakage cause rises in price to cover the costs of repairs to the leaks or to cover the higher costs of pumping the additional water which ends up leaking. While we cannot rule this explanation out, we are doubtful about its relevance because in practice the Tunisian Ministry of Agriculture sets prices that barely cover the cost of operating and maintaining the water delivery system, let 
alone the cost of building the infrastructure.

Testing hypotheses about the determinants of theft in cooperatives is a major empirical challenge, since many of the features of the institutional environment that are empirically associated with incentives for theft are not exogenous features of the environment, but evolve in response to environmental characteristics that themselves influence theft, and may even evolve in direct response to perceived theft levels ${ }^{2}$. Our procedure is to use theory to focus attention on the underlying determinants of both institutional structure and (together with institutional structure) of individual behavior. The theory then guides our search for proxies for unobserved variables, and instruments for observed but endogenous variables, that enable us to identify the appropriate causal relationships (there is a bidirectional causal relationship between institutions and incentives: institutions do affect the behavior of individuals; but institutions themselves evolve endogenously with the environmental characteristics) in our data, which come from an original survey conducted by one of us in Tunisia. We find that a variable that plausibly proxies for monitoring costs can influence theft, in the sense that higher monitoring costs make theft easier. We also find that the incidence of theft is affected by aspects of the institutions - the rules specifying how severely individual members will be punished for theft, and the overall number of members in the cooperative, which influences the scope for free-riding. However, measuring this relationship requires us in turn to see how various constraints affect the way in which these institutions evolve. Once we have accounted for the potential endogeneity of institutional characteristics, we find support, as predicted, for the hypotheses that larger cooperatives entail more theft, and higher punishment levels reduce theft. Nevertheless, other economic, socioeconomic, physical, personal and geographical factors seem to be relevant for the design of cooperatives and farmers' decisions, and some of these factors are considered in the empirical analysis. 
The article is structured as follows. In section 1, we revise the mainly related literature. Section 2 sets out our model. We state a proposition in the cooperative institution describing the dependence of theft on a number of determinants, some of which are themselves determined by more fundamental factors including costs of monitoring. We use this proposition to make predictions that can be tested empirically. Section 3 describes our data and tests the theoretical predictions. Section 4 concludes. Mathematical details and some interesting extensions are relegated to an appendix.

\section{Related literature}

Our study fits in partially with the line of research on peer-monitoring in group lending programs where peer-monitoring (see Wade 1987, an early contribution to what is now a large literature.) has been recognized as an effective instrument for mitigating the moral hazard behavior of group members who are linked by a joint-liability clause. Though not the same, the issues tackled in this article have also some similarities to the problem of nonpoint source pollution ${ }^{3}$, where unobserved individual emissions can be regulated through instruments that are conditioned on observed aggregate (ambient) pollution.

In the peer-monitoring literature, the joint-liability clause creates an incentive mechanism in which each member has an interest in screening and monitoring the other members, and to enforce repayment if necessary. In practice the use of peer-monitoring arrangements has been extensive, particularly in developing countries. However, results as measured by repayment rates, have been mixed, according to a large number of descriptive and empirical articles on the subject. These articles have inspired various theoretical contributions. The seminal publications in this area are Stiglitz (1990) and Varian (1990), where peer-monitoring within groups can prevent members' shirking in their productive efforts (Varian) and poor project selection (Stiglitz). Group lending 
programs delegate monitoring to group members, improving thereby repayment rates and reducing the costs of lending, which may be translated into lower interest rates borrowers have to pay (Varian) and larger loan contracts (Stiglitz).

More recently several papers elaborate on the Stiglitz-Varian models, relaxing the assumption of the costless monitoring and dealing with other extensions, Armendariz De Aghion (1999), Ghatak and Guinnane (1999), Che Koo (2002), and Conning (2005). These papers are also concerned with delegated monitoring, and by comparing individual liability to joint-liability loans. While emphasizing the benefits of delegated monitoring, most articles (except for Armendariz De Aghion 1999) rule out ex-post "strategic default" considerations and focus instead on ex ante moral hazard. De Aghion develops a model of strategic default where a borrower's partner(s) can verify her true project return (and impose sanctions if she defaults strategically, where sanctions are given) at some cost and allows for project returns of group members to be correlated. She examines the issue of optimal design of group-lending programs in terms of optimal diversification of risks within peer borrowers, the optimal group size and monitoring structures.

Che Koo (2002) develops a model where repeated loan contracts are offered to borrowers. He demonstrates that without introducing an $a d$-hoc penalty technology, the joint-responsibility clause itself makes it credible for members to penalize others through their effort decisions. If the group members can observe the other members' efforts decisions, they can employ a punishment strategy whereby a shirking member is retaliated by a subsequent shirking by her peers. When such a punishment strategy is self-enforcing, group lending can alleviate the incentive problem facing the members.

Conning (2005) develops a model where he analyzes the conditions under which joint-liability loans are more beneficial than outside monitored loans. Such benefits do not rest upon a presumed 
information or enforcement advantage held by insiders but instead on an incentive diversification effect that cannot be replicated by outside intermediaries. The subdivision of the original project into smaller independent sub-tasks and financing them together reduces the overall minimum collateral requirement relative to the individual liability alternatives of either separate "unlinked" individual contracts for each task, or the original undivided project. Joint-liability clauses are chosen to implement a preferred Nash equilibrium in a multi-agent, multi-task game, where each borrower is given incentives to remain diligent as financed entrepreneur and as a monitor of others. The model also discusses the effects of collusion among borrowers on group lending efficiency. A lender will guard against this possibility by only agreeing to collusion-proof loans.

Whereas the theoretical literature on peer-monitoring and moral hazard within group lending programs is quite extensive, there are only very few empirical studies of these phenomena. One possible explanation is that it is difficult to obtain reliable data on these issues. To our knowledge the only two substantial studies available are carried out by Wydick (1999), and Hermes et al. (2000), who use information from group lending programs in Guatemala and Eritrea respectively. Wydick analyzes the role of peer-monitoring, peer pressure and social ties within theses groups in reducing the moral hazard behavior of borrowers. His findings show that while peer-monitoring and (to a lesser extent) peer pressure help to reduce moral hazard and increase the repayment performance of groups, social ties do not have such effects. Hermes found support for the fact that peer-monitoring and social ties of group leaders do help reducing moral hazard, however, this was not the case of the other members.

In the literature on nonpoint source pollution, recent policy emphasizes the team nature of the problem by proposing economic instruments based on collective performance which is the level of observed aggregate (ambient) pollution. This strand of literature follows the pioneering work 
of Segerson (1988) whose analysis builds on earlier theoretical analysis of Holmström (1982) who addresses the problem of free riding in teams in more general environment. A main finding of Holmström is that in the absence of uncertainty, no budget balancing mechanism exists to solve the problem for avoiding individual free riding in teams. In her pioneering work, Segerson, proposed a tax/subsidy mechanism based on group performance to promote socially optimal behavior. She suggested that the regulator should monitor ambient pollution concentrations and tax (subsidize) the polluters when ambient pollution levels are above (below) an exogenously determined level which is considered as socially optimal by the regulator. In this scheme each polluter is charged a unit tax based on the aggregate level of pollution, meaning, that the liability of each polluter depends on the abatement effort of all polluters, not just her own. When assuming damage as linear in the ambient pollution level, Segerson demonstrated that the ambient tax/subsidy rule ensures a firstbest outcome without observing individual pollution levels. Furthermore individual monitoring was demonstrated superfluous also in the non-linear case as long as the transport mechanism is identical for all polluters. Segerson's model assumes that polluters are risk neutral and their number is small enough, that they understand that their decisions affect aggregate emissions - polluters assume non-cooperative Nash behavior.

Segerson's ambient tax has inspired several intriguing extensions. Xepapadeas (1991) suggested a scheme of subsidies and random fines aimed to eliminate the moral hazard problems with budget balancing contracts - in his contribution Xepapadeas studies two different fining regimes: collective and random fining. Under collective fining all the firms are fined whenever the observed ambient pollution level lies above some predetermined standard. Under the random fining scheme, by contrast, only one firm is randomly chosen to be punished, irrespective of being responsible for the whole group's deviation from the standard level. Meanwhile, the other producers receive a portion 
of the fine minus the damages to society. Herriges et al (1994) illustrate that such an incentive system could be effective at increasing costs of shirking if polluters are sufficiently risk-averse.

Miceli and Segerson (1991) suggested the introduction of liability rules among parties that actually create incentives that are similar to the ones created by ambient taxes. However, as noted by Lichtenberg (1992), liability rules are not likely to be first-best and are probably best suited for the control of pollution related to the use of hazardous materials, or for non-frequent occurrences of environmental degradation like oil spills.

Karp (2002) proposed a model in which polluters behave strategically with respect to the taxsetting regulator, and found that their tax burden is lower under an ambient tax than taxes based on individual emissions, provided that: the tax adjusts quickly, firms are patient, and the number of firms is small. Firms may prefer the case where the regulator is unable to monitor individual emissions, even if the asymmetric information causes the regulator to tax each firm on the basis of aggregate emissions.

Millock and Salanié (2005), extend the theory of ambient taxes to the case when polluters might cooperate. They show that ambient taxes provide strong incentives towards cooperation. However, when the degree of cooperation among polluters is unknown, the optimal regulation requires the regulator to offer a choice between a standard Pigouvian tax and a much lower ambient tax.

There has been substantial experimental ${ }^{4}$ research on ambient pollution based policies for addressing nonpoint source pollution (Alpizar, Requate and Schram 2004; Cochard, Willinger, and Xepapadeas 2005; Poe et al. 2004; Spraggon 2002; Sutter et al. 2008; Vossler et al. 2006). These experimental research has evaluated static regulatory mechanisms under the assumption that the regulator has complete information from which to parametrize the optimal policy instrument. Evidence from this research suggests that the ambient tax/subsidy mechanism is likely to be efficient 
in small group settings of non-cooperating agents whereas, not efficient if agents are allowed to cooperate (Vossler et al. 2006). The argument is that the ambient tax/subsidy mechanism creates incentives for polluters to cooperate and agree on abatement strategies to reduce their expected tax payment (Hansen 1998; Vossler et al. 2006). The reason is that this strategy benefits the group as a whole because each unit of abatement reduces the return of only one polluter while all polluters in the group benefit from additional subsidies.

Our model differs mostly from the existing theoretical literature on peer-monitoring in two respects. Firstly, in their models the punishment is fixed: in case of non repayment by the group, all members will be denied future access to loans from the program, and otherwise, defaulters who are caught may face fixed social sanctions. However, in our model the punishment depends continuously on the level of theft undertaken by farmers. Secondly, Peer-monitoring in this paper is quite specific in that players are competing in monitoring which gives rise to two effects rather than one as it is the case in the peer-monitoring theoretical literature. Indeed, in the existing literature peer-monitoring has only an incentive effect, it aims to mitigate the moral hazard behavior. In turn, in our model peer-monitoring aims not only to reduce the incentives of theft (incentive effect), but it may also allow each cooperative member to shift the cooperative fine on the others (distributional effect).

Moreover, to the best of our knowledge, neither of the empirical studies on peer-monitoring has come close to how individuals choose their institutional rules (ignoring thereby the potential endogeneity of institutional characteristics) and also how these rules affect the individuals' behavior.

As for the ambient tax literature, it differs from our work in several respects. First, in our article the collective responsibility rule creates incentives for peer-monitoring by group members (a substitute instrument of punishment for mitigating the moral hazard behavior), while, ambient 
taxes do not. Second, ambient taxes are charged to all polluters within the area, whenever, the ambient pollution concentration deviates from a level which is considered as socially optimal by the regulator. Unlike, in our article there is no predetermined threshold for the amount of water stolen, punishment is implemented whenever, theft occurs. Third, the principle of the ambient tax is that each individual is taxed according to the social marginal damage when ambient emissions deviate from some exogenously determined level. In turn in our work, the distribution of the punishment burden is endogenously determined by monitoring. Fourth, in our study whether efficiency obtains or not depends on the stringency of the punishment rate, however, most of mechanisms suggested in the ambient tax literature are theoretically suitable to implement the efficient allocation of abatement efforts in Nash equilibrium.

\section{The model}

Our model is a deliberately simplified structure designed to capture some features of real-world cooperative water management while consciously abstracting from others. It makes no claim to be considered an optimal mechanism: instead, we take as given some features of real-life institutions without enquiring into their optimally properties, and use them to ask how the agents operating within them would attempt to optimize, and whether they are doing so efficiently subject to their constraints. In particular, we shall consider a two-agent model, with a very restricted strategy set for the agents, and we shall look only at symmetric equilibria. Nevertheless, even in this restricted setting certain features emerge that we believe to be both interesting and empirically relevant.

Consider two identical risk-neutral farmers who produce a homogeneous farm good using water as an input. The yield $(y)$ response to water $(q)$ can be described by the relation $y=g(q)$, where $g($.$) is an increasing and strictly concave function. The cost incurred by each farmer for using$ 
water, measured in units of output, is $c$ per unit of water. In addition the farmer pays a linear price $t$ per unit of water used, a price which is determined by the Water Authority (hereafter WA). The profit-maximizing quantity of water equates the marginal value product of water to the marginal cost of generating such a quantity

$$
g^{\prime}(q)=c+t
$$

In the absence of asymmetric information, and abstracting from any shadow cost of public funds that might imply Ramsey-pricing considerations, the WA can implement the first-best efficient outcome by setting $t$ equal to $\gamma$, which represents the full public cost of resource provision, including O\&M costs, investment costs, extraction externalities associated with pumping from a shared aquifer and any shadow cost associated with the scarcity of water.

However, when the individual farmer's water use is her private information (unlike the total amount of water use by farmers which is observable to the WA), the farmer who is equipped with an individual water meter can send a report of the amount used, denoted by $q^{r}$, that may differ from the true quantity. We write the amount of water stolen as $a=q-q^{r}$. We assume that there are no rewards for over-reporting.

The response of the WA will differ according to whether there is centralized or cooperative management ${ }^{5}$. Though centralized management is interesting it is not central to our empirical study; we have therefore included a model of this phenomenon in the appendix.

\subsection{Cooperative management}

We assume that the total amount of water used by the two cooperative members, $Q=q_{1}+q_{2}$, is publicly and costlessly known, and can thereby serve as a basis for aggregate payments from the cooperative to the WA. In particular, this allows for a joint-liability rule: if theft occurs, the 
cooperative as a whole receives a punishment proportional to the total amount of water stolen (which is publicly observable). The punishment is measured in terms of the length of time for which water is cut off from the whole cooperative when theft occurs. This length is proportional to the total amount of water stolen in the cooperative. The punishment is assumed to take the form:

$$
F^{c}=f\left(\sum_{i=1,2} q_{i}-\sum_{i=1,2} q_{i}^{r}\right) .
$$

where the punishment rate $f$ is positive and given outside the model. The solution to the cooperative management will be indexed with the superscript " $c$ ".

Suppose that, relative to the WA, farmers have a comparative advantage in monitoring each other, as a result of geographical proximity and/or long-standing trade links. We assume that peer-monitoring brings about only evidence of the occurrence of theft but not of its amount ${ }^{6}$. The WA may then contemplate the possibility of inducing peer-monitoring between the two farmers, typically through the establishment of a cooperative governed by rules that make all members jointly liable ${ }^{7}$. If theft occurs in the cooperative, the fine is shared equally between farmers who are caught stealing; otherwise it is shared by all members.

Peer-monitoring incurs a private cost $\psi(m)$ to a farmer, assumed to be increasing, convex and satisfies $\psi^{\prime}(0)=0$. Each member commits to a level of monitoring ${ }^{8}$ (observable by other members) before actual and reported water uses are decided. The probability that a farmer $i$ is caught stealing is then given by:

$$
P_{i}\left(m_{j}, a_{i}\right)=\kappa m_{j} \max \left\{a_{i}, 0\right\} .
$$

where $\kappa>0$ (we assume henceforth that it is sufficiently small to generate an interior solution, which is realistic). This probability is increasing in the farmer's own level of theft and the monitoring 
effort of the other. Farmers do not collude in either their monitoring or their production decisions ${ }^{9}$. The order of events is therefore that the WA fixes ${ }^{10} t$, then individual members choose $m_{i}$, then having observed each others' choice of monitoring they choose $q_{i}$ and $q_{i}^{r}$. The outcome will depend on the severity of the punishment rate. If it is sufficiently high, there will be no theft and no monitoring in equilibrium (since this ensures that the collective punishment is sufficient to deter theft). Otherwise, there will be positive theft and positive monitoring in equilibrium (it is this latter case that will be important for our empirical testing). Summarizing:

PROPOSITION 1: If $f \geq 2 t$, there exists a unique symmetric subgame perfect equilibrium $\left(m^{c}, a^{c}\right)$ such that

$$
m^{c}=a^{c}=0
$$

If ${ }^{11} t<f<2 t$. Then, the unique symmetric subgame perfect equilibrium $\left(m^{c}, a^{c}\right)$ satisfies

$$
a^{c}=\frac{(2 t-f)}{2 \kappa m^{c} f}
$$

and

$$
m^{c}: \frac{(2 t-f)(2 f-t)}{4 \kappa\left(m^{c}\right)^{2} f}=\psi^{\prime}\left(m^{c}\right)
$$

Proof: See the Appendix.

Peer monitoring not only reduces the incentives for theft (incentive effect) but may also allow each cooperative member to shift the cooperative fine on to the other (distributional effect ${ }^{12}$ ). 


\subsection{Comparative statics with quadratic monitoring costs}

To obtain explicit solutions where possible we assume that monitoring costs take the quadratic form $\psi(m)=\frac{1}{2} b m^{2}$ where $b>0$. We first explore the impact of monitoring costs, water price and the level of punishment on the equilibrium monitoring effort. As one might intuitively expect, monitoring levels are decreasing with the cost parameter $b$, increasing with water price and decreasing with the punishment rate $\mathrm{r}^{13}$

$$
\begin{gathered}
\frac{\partial m^{c}}{\partial b}=-\frac{m^{c}}{3 b}<0 \\
\frac{\partial m^{c}}{\partial t}=\frac{1}{12 b} \frac{(5 f-4 t)}{\kappa\left(m^{c}\right)^{2} f}>0
\end{gathered}
$$

and

$$
\frac{\partial m^{c}}{\partial f}=\frac{\left(t^{2}-f^{2}\right)}{6 \kappa b\left(m^{c}\right)^{2} f^{2}}<0 .
$$

Secondly, we study the relationship between the monitoring level ${ }^{14}$, the price of water, the punishment rate and the incidence of theft in equilibrium. As the intuition suggests theft is decreasing with monitoring and punishment levels and increasing with the price of water ${ }^{15}$ :

$$
\begin{gathered}
\frac{\partial a^{c}}{\partial m}=\frac{(2 t-f)}{2 \kappa f}\left(-\frac{1}{\left(m^{c}\right)^{2}}\right)<0 \\
\frac{\partial a^{c}}{\partial f}=\frac{\left(2 t^{2}+f^{2}-6 f t\right)}{3 \kappa m^{c} f^{2}(2 f-t)}<0
\end{gathered}
$$

and

$$
\frac{\partial a^{c}}{\partial t}=\frac{1}{6 \kappa m^{c} f} \frac{(7 f-2 t)}{(2 f-t)}>0 .
$$


It is interesting to explore whether the equilibrium monitoring effort is efficient. For this purpose, we compare the equilibrium monitoring level to that which would occur in a second-best problem faced by the WA as a social planner who can set monitoring decisions of farmers but not their water use choices, nor their reports once monitoring decisions have been made. Moreover, assume that the WA cannot affect the incentives of theft for given monitoring efforts. In particular, the WA cannot ensure that farmers do not steal. The WA picks a monitoring effort that maximizes the social welfare function defined as the sum of the farmers' surpluses, $2\left[g\left(q^{c}\right)-c q^{c}-t q^{r c}-f a^{c}(m)\right]$ plus the surplus of the WA, which is equal to its revenue from water proceeds $2 t q^{r c}$, from which is deducted the cost of supplying water to the cooperative area $2 \gamma q^{c}$ and the cost of performing monitoring, $2 \psi(m)$

$$
W^{c(s b)}(m)=2\left[g\left(q^{c}\right)-(c+\gamma) q^{c}-f a^{c}(m)-\psi(m)\right] .
$$

The solution to the cooperative in the second-best will be indexed with the superscript " $c(s b)$ ". $a^{c}(m)=\frac{(2 t-f)}{2 \kappa m f}$ is the amount of water stolen by a farmer in the symmetric equilibrium when cooperative members non-cooperatively choose how much water to use and to steal taking for given the level of monitoring performed by the WA. The (second-best) efficient monitoring level which equates the marginal reduction of the total cooperative fine to the marginal cost of monitoring satisfies

$$
\frac{(2 t-f)}{2 \kappa\left[m^{c(s b)}\right]^{2}}=\psi^{\prime}\left(m^{c(s b)}\right)
$$

We show that, for the case of quadratic monitoring costs, the equilibrium monitoring effort is 
lower than the (second-best) efficient level for reducing theft, i.e., $m^{c}<m^{c(s b)}$, where

$$
m^{c(s b)}=\left(\frac{2 t-f}{2 \kappa b}\right)^{\frac{1}{3}} \text { and } m^{c}=\left(\frac{(2 t-f)(2 f-t)}{4 \kappa b f}\right)^{\frac{1}{3}}
$$

This is because, in addition to reducing the incidence of theft, monitoring increases the risk that the party performing monitoring will have to bear the whole punishment ${ }^{16}$, and this second effect (which is purely distributional) acts as a disincentive to undertaking the efficient level of monitoring.

\section{$2.3 \quad$ Endogenous punishment}

Here we extend the model to the punishment rate $f$ to be chosen collectively by cooperative members at an initial contracting stage, subject to a cost of inflicting punishment $\varphi(f)$ which is increasing and sufficiently convex ${ }^{17}$ to ensure an interior solution. This cost may be pecuniary or may correspond to costs in the deterioration of social relations that occur when punishment is inflicted on members of a close-knit society. Members choose the punishment level $f^{c}$ that maximizes an objective function

defined as the sum of cooperative members' surpluses $2\left[g\left(q^{c}\right)-c q^{c}-t q^{r c}-f a^{c}-\frac{1}{2} b\left(m^{c}\right)^{2}\right]-\varphi(f)$ to which we add the WA's surplus equal to its revenue from water proceeds $2 t q^{r c}$, from which is deducted the cost of supplying water to the cooperative area $2 \gamma q^{c}$.

$$
\max _{f \in(t, 2 t)} W^{c}(f)=2\left[g\left(q^{c}\right)-(c+\gamma) q^{c}-f a^{c}-\frac{1}{2} b\left(m^{c}\right)^{2}\right]-\varphi(f)
$$

This has a first-order condition ${ }^{18}$ :

$$
f^{c}: \frac{1}{3 \kappa f^{2} m^{c}(2 f-t)}\left(6 f^{3}+t^{3}-4 f^{2} t\right)=\varphi^{\prime}(f),
$$


which is also sufficient to identify a global maximum ${ }^{19}$.

From this we can show that the punishment level is increasing with monitoring costs. Totally differentiating the first-order condition with respect to $f$ and $b$ and rearranging yields:

$$
\frac{\partial f^{c}}{\partial b}=-\frac{1}{\left(\frac{d^{2} W^{c}(f)}{d f^{2}}\right)} \frac{\left[6\left(f^{c}\right)^{3}+t^{3}-4\left(f^{c}\right)^{2} t\right]}{3 \kappa\left(f^{c}\right)^{2}\left(2 f^{c}-t\right)}\left(-\frac{1}{\left(m^{c}\right)^{2}} \frac{\partial m^{c}}{\partial b}\right)>0 .
$$

The above expression is positive because $\frac{\partial m^{c}}{\partial b}<0$ and $\left(\frac{d^{2} W^{c}(f)}{d f^{2}}\right)<0$. This result shows that the two instruments, monitoring and punishment, are substitutes.

\subsection{Cooperative size}

The analysis thus far has remained restricted to the two-farmer cooperative. In practice, however, most cooperatives for which irrigation is based on aquifers involve up to as many as 40 farmers, and most involve more than 100 farmers when irrigation is based on surface water. Unfortunately it is quite difficult to find analytical solutions for optimal cooperative size, but in a companion paper we report simulations suggesting (though they do not prove) two relationships that we shall examine further in our empirical section below. First, the incidence of theft appears to increase with the cooperative size (the reason it is hard to show this analytically is that while cooperative size apparently increases the incentives of members to free-ride on monitoring ${ }^{20}$ as well as to steal from each other, it also increases the maximum punishment that would be incurred by a member who was the only one to be caught, which acts as an incentive in the opposite direction). Secondly, the optimal cooperative size appears to be (weakly) decreasing with monitoring costs (higher monitoring costs reduce the incentives for monitoring, increasing therefore the opportunities of theft, and smaller is the cooperative to compensate). 


\subsection{Summary of empirical hypotheses}

The predictions of the models set out above are as follows:

- Theft increases with the price of water

- Theft decreases with punishment levels

- Theft increases with monitoring costs

- The optimal level of punishment increases with monitoring costs

The predictions of the simulations in Mattoussi \& Seabright (2007) are as follows:

- Theft increases with the cooperative size

- The optimal cooperative size decreases with monitoring costs

\section{Testing the Model: Data}

This section tests our predictions using survey data from 2001-03 for 49 irrigation cooperatives, the so called Collective Interest Groups CIG in five governorates in the north of Tunisia. The key question for investigation is what determines the rate of theft of water, a highly scarce resource in this region. Among the difficulties in testing such predictions are that some of the likely determinants of theft (such as monitoring levels) are not observable, at least by the econometrician, while others (such as cooperative size and punishment levels) are very likely to be endogenous.

There is also the difficulty that theft as such is not observable. What we do observe is the difference between total water used by each cooperative and the aggregate amount reported by cooperative members' water meters. It is possible that some of this difference may be due to 
technical problems such as leakage from pipes. This is why the WA deducts from the previous measure an estimate of likely losses due to leakage, that varies with the age of the irrigation system (these losses are measured as a proportion of water distributed to the cooperative minus 10 percent for systems under 10 years old and 15 percent for older systems) as well as an estimate by the WA of leakages due to known breakages in pipes. This measure corresponds to the (estimated) total amount of water theft in the cooperative.

The survey was carried out by one of us in five governorates of a northern region of Tunisia, a country which faces growing scarcity of water. Government policies for the last three decades have promoted irrigated cropping patterns at the expense of dryland farming. As a consequence there has been an increase in water use in the agricultural sector. At the same time the expansion of the other major sectors of the economy (industry and tourism) has increased competing water demands outside the agricultural sector. In addition a relatively cheap pricing policy, where irrigation water is charged at its average variable cost rather than its long-run marginal cost, has led to a choice of cropping patterns where low value and/or water-intensive crops are grown. Indeed, despite the country's comparative disadvantage in water-intensive crops, the main exported farm goods are dates and citrus fruits whose water consumption averages $15.000 \mathrm{~m}^{3}$ and $10.000 \mathrm{~m}^{3}$ per hectare respectively. In this agro-climatic zone, wheat, olives and gardening products are the main crops in the winter season, with wheat by far the most important in terms of cultivated area $(76.7 \%)$. Tomatoes, watermelon, potatoes, grapes, apples and pears are the main crops in the summer season. The region receives moderate and erratic rainfall averaging $570 \mathrm{~mm}$ per year, mainly concentrated during the winter season from December to February. Farmers therefore rely heavily on water sources controlled by water agencies for the remainder of the year. The region is mostly flat, with hills in only 30 percent of its total area. One distinguishing feature of the governorates under study 
is that they vary considerably with respect to geographical and socioeconomic characteristics (see Mattoussi, 2006 for further details).

A centralized mode of regulation dominated water management in the country until 1987 except in the south, where in the region of "Djerid", a system of participatory management has been in place since the XIII century. Under the latter system, the distribution of water in the oases was held by a "syndic" chosen by the beneficiaries, assisted by the "Kbar" (community elders). Under centralized scheme, management responsibilities of regional authorities in charge of running public irrigated areas on behalf of the Central Water Authority the so called "Agricultural Regional Development Commissions" (ARDC) include providing public areas with water, dealing with the operation and maintenance of irrigation systems, replacing equipment, monitoring farmers to reduce the occurrence of theft when areas are equipped with measuring devices, collecting water proceeds, and so on. However, since 1987, participatory management was implemented through CIGs the socalled "Collective Interest Groups", have become a central component of governmental reforms in the water sector. The participatory approach speeds up the transfer of water management from the administration to beneficiaries in the period between 1987 and 2003, the number of CIGs increased from 100 to over 1000 . The simplest water distribution plan is that related to rural drinking water, then come small and medium scale irrigation networks whose areas vary between 20 ha and 700 ha. CIGs for irrigation cover 56 percent of irrigated areas equipped by public investment, with a total surface area of 121.000 hectares. CIGs began by assuming energy costs first, extending afterwards to salaries of pump attendants, thus relieving the state from all energy and personal costs. The ARDC's still support simple CIGs for major maintenance works and replacement of equipment. They also set water tariffs for the CIGs of the region, and decide about the area covered. The main question is how these areas are covered? Such a decision is based on a technical study conducted 
by the Ministry of Agriculture. The area covered is also influenced by geographical constraints and inferior infrastructure (for instance, areas might be bordered by water streams such as rivers, by mountains or/and by main roads or highways...etc.).

Most governorates of the survey have experienced participatory management since 1989 at the exception of Zaghouan for which such management was introduced in 1960 through the project of "Jenan Zaghouan". In 2003 the region contained more than 482 CIGs of which 182 are for irrigation; the latter manage 58,8 percent of its public irrigated areas.

Our target population is CIGs equipped with individual water meters which number is 95 in the whole country. Only 49 of these 95 CIGs are permanently functioning and had data available of the kind needed for our study (for instance, data about cooperative accounts, including information about the total amount of water delivered to the cooperative, the total reported usage indicated by the members' water meters, estimated water losses due to leakages, cropping patterns, diffusion of drip and sprinkler-irrigation systems and so on). We are not aware of any biases that might be introduced into our results by this partial availability of data, but evidently the possibility of selection bias cannot be ruled out.

Our data consist of information about the number of cooperative members ${ }^{21}$, the price of water charged to farmers, as well as about the socioeconomic characteristics of cooperatives managers (members who are in charge of running cooperatives' affairs), such as their level of education and their age. We also have information about geographical characteristics, such as the percentage of cooperatives' area which are hilly and the sources of water supply available to farmers, including those not controlled by Government agencies. In addition there are data about pedologic characteristics as the percentage of the cooperative area which soil is red; and about the cooperatives' cultivation processes, namely cropping patterns and the diffusion of drip and sprinkler-irrigation 
systems.

The data are of an unbalanced panel type, for 3 years from 2001-03 for 39 cooperatives and for 2 years from 2002-03 for the remaining 10. Almost all data were jointly provided by the Agricultural Regional Development Commissions (ARDC) of the five governorates, by the "technical directors" of cooperatives who are in charge of the cooperatives' accounting operations, by the pumping attendants when supply sources are boreholes and by the Central Water Authority when some data are not available for some cooperatives. Only a few data were exclusively collected from cooperatives managers. We also obtained information from the cooperatives' managing authorities about the types of natural catastrophes that had stricken cooperatives and the extent of damage they caused, and we also cross-checked our estimates of losses in cooperatives' production with the Cells of Agricultural Development (CAD) of the five governorates. We also asked about the prices of farm goods produced by the region in the previous and current seasons.

Before proceeding with the econometric analysis it is important to clarify the way in which we propose to measure the monitoring costs faced by the cooperative.

\subsection{Proxy measure of peer monitoring costs}

Given that monitoring levels are not directly observable, we need to find a suitable proxy measure.

- DISTANCE: the length of the main road's portion (measured in kilometers) separating the entrances of the cooperative area and the agglomeration (entrances are officially determined by municipalities where the agglomeration and the cooperative are located).

This is likely to increase monitoring costs because it reduces the ability of cooperative members to observe the behavior of other members as a by-product of their own day-to-day activities. 
It is important to note that monitoring costs cannot by themselves be used as excluded instruments for the endogenous variables, since the theory predicts that monitoring costs will determine both the choice of institutions (such as the cooperative size and punishment rate), and also the level of theft conditional on that institutional choice. However, we can nevertheless investigate whether monitoring costs also directly influence the choice of institutional characteristics; we do this in section 4 below. Table 1 shows the descriptive statistics of each variable. The variables we will use in the subsequent empirical analysis are defined as follows:

- ADVERSE CLIMATE: scores $(+2)$ when the cooperative faces both peak heat higher than 40 degree Celsius in the shadow during the three months of July, August and September, and lower than average annual precipitation (lower than $500 \mathrm{~mm}$ ). It scores $(+1)$ when it faces either peak heat higher than 40 degree Celsius in the shadow during the three months of July, August and September, or lower than average annual precipitation (lower than $500 \mathrm{~mm}$ ) and scores (0) otherwise.

- AGE: the average age of farmers who are in charge of running the cooperative.

- ALTERNATIVE REVENUE: it scores $(+1)$ when more than 10 percent of cooperative members have income from off-farm sources, and scores (0) otherwise.

- ALTERNATIVE SOURCE: the percentage of active farmers who have alternative sources of water supply which are not controlled by the Agricultural Regional Development Commissions (ARDC), such as lakes and/or rivers.

- DENSITY: the number of individuals living in the agglomeration (village or little town).

- where the cooperative is located, divided by the surface of the agglomeration (measured in hectares). 
- DISTANCE TO LARGE CITY: the distance (measured in kilometers) between the cooperative area and the nearest large city where there are public infrastructures such as schools, public hospitals, water systems, bridges, roads and other public buildings.

- DRIP: the percentage of the land irrigated by the cooperative equipped with drip irrigation systems.

- EDUCATION: the average number of years of schooling of farmers who are in charge of running the cooperative's affairs.

- EQUIPPED SURFACE: the surface of the cooperative area (measured in hectares). This area is equipped with irrigation network, e.g., primary and secondary water tubes, measuring devices and so on.

- HILLY AREA: the percentage of the cooperative area which is hilly.

- PREVIOUS SPRINKLER: the percentage of the land irrigated by the cooperative which was equipped with sprinkler systems in the previous year.

- PRICE: the price of one unit of water (i.e., the number of Tunisia Dinars per $\mathrm{m}^{3}$ of water used by the farmer) charged by the WA to the cooperative.

- PUNISHMENT RATE: the number of days for which farmers are denied access toirrigation, expressed per $10.000 \mathrm{~m}^{3}$ of divergence between the estimated water used by cooperatives members $^{22}$ and the total amount of water indicated by the members meters. This divergence represents the total liability which will be shared between members who are caught stealing.

- SIZE: the number of active farmers who grow crops on land irrigated by the cooperative. 
- RAINFALL: this is a somewhat crude measure of the variation in the annual precipitation the region where the cooperative area is located, faces. It scores $(+2)$ when it faces high annual precipitation (higher than $600 \mathrm{~mm}$ ). It scores $(+1)$ when it faces normal annual precipitation (between $600 \mathrm{~mm}$ and $200 \mathrm{~mm}$ ); and scores (0) when it faces lower than normal annual precipitation (lower than $200 \mathrm{~mm}$ ).

- RED SOILS: the percentage of the cooperative area which soil is red.

- REVENUE SHOCK: this is an index, drawn up in discussion with the representatives of each cooperative, capturing whether the cooperative had experienced a good or bad previous year relative to what is perceived as normal. It scores (-2) when more than 50 percent of the cooperative area was ravaged in the previous year by some natural catastrophes as floods, scorching heat and crops diseases, and in addition there was a decrease in the prices of the main farm goods produced by the cooperative. It scores $(-1)$ when up to 50 percent of the cooperative area was ravaged by some natural catastrophes as floods, scorching heat and crop disease, and moreover there was no major change in the prices of the main farm goods produced by the cooperative. It scores (0) when farmers enjoy favorable environmental conditions and there was no rise in the prices of the main farm goods produced by the cooperative. It scores $(+1)$ when farmers enjoy favorable environmental conditions and there was a small rise in the prices of the main farm goods produced by the cooperative. It scores $(+2)$ when farmers enjoy favorable environmental conditions and there was a significant rise in the prices of the main farm goods produced by the cooperative.

- WATER SOURCE: scores $(+4)$ when the source is a dam which storage capacity is between 400 and 700 millions of $\mathrm{m}^{3}$ of water (qualified as a big dam). It scores $(+3)$ when the source is a dam which storage capacity is between 50 and 400 millions of $\mathrm{m}^{3}$ of water (qualified as a 
medium dam). It scores $(+2)$ when the source is a dam which storage capacity is between 10 and 50 millions $\mathrm{m}^{3}$ of water (qualified as a small dam). It scores $(+1)$ when the source is a dam which storage capacity is between 1 and 10 millions of $\mathrm{m}^{3}$ of water (qualified as a very small dam) or it is a hilly lake. It scores (0) when the source is a borehole ${ }^{23}$.

- WATER THEFT: the differential between estimated water used by cooperatives members (equal to the total amount of water delivered to the cooperative area from which the WA deduces an estimate of likely losses due to leakage, that varies with the age of the irrigation system - these losses are measured as a proportion of water distributed to the cooperative minus 10 percent for systems under 10 years old and 15 percent for older systems, as well as an estimate by the WA of leakages due to known breakages in pipes) and that indicated by cooperative members' meters, expressed as a percentage of the estimated water used by members.

\subsection{Testing the Model: Results}

In this section we report the determinants of water theft using various specifications including the instrumental variables regression to deal with the endogeneity of the institutional characteristics and technological adoption. We then report more detailed econometric evidence about how people involved in the cooperative determine the institutional characteristics, notably the punishment rate and the cooperative size.

\subsubsection{Estimation of the determinants of water theft}

We report here the determinants of theft - in particular, the predictions that theft is increasing with the price of water, decreasing with the punishment rate, and increasing with the cooperative 
size and monitoring costs. We regress water theft on the following independent variables:

- PRICE

Institutional variables:

- PUNISHMENT RATE.

- SIZE.

Variable controlling for water productivity:

- DRIP.

Proxy measure of monitoring costs:

- DISTANCE.

Control variables

- AGE.

- EQUIPPED SURFACE.

- REVENUE SHOCK. This index captures the broad characteristics of a shared revenue shock (some crude measure of losses incurred by the cooperative in previous seasons) and can thereby be considered as a proxy measure of cooperative members liquidity constraints. As will be seen below this variable is associated with water theft in an entirely intuitive direction.

Table 2 illustrates an Ordinary Least Squares estimation of the determinants of water theft. The two first equations (which are OLS regressions with clustering on cooperatives) show that theft increases with the price of water, the cooperative size and the distance of the cooperative from the 
village. It is decreasing with the punishment rate. These four effects are all those predicted by the theory, and all are significant at $1 \%$ except the price effect which is significant at $5 \%$.

The third equation shows that the qualitative findings prove reasonably robust to the inclusion of cooperative fixed effects, although this is a very demanding test since there are only three years of data and then not for all cooperatives. Under fixed effects the standard errors increase, reducing the price effect to insignificance (though without very much modifying the coefficient). Overall, though, the results clearly support the predictions of the theory, the remaining coefficients show various controls for which theory provides no unambiguous predictions. The presence of drip irrigation (which increases the productivity of water) lowers theft. The age of the cooperative manager has a positive effect on theft but this is reversed under fixed effects. The presence of a positive revenue shock lowers theft (though not in the fixed effects specification), as does the size of the equipped surface.

We now turn to concerns about the possible endogeneity of some of the right-hand side variables (using the IV regression with clustering on cooperatives). The most likely variable to suffer from this problem is PUNISHMENT RATE: higher rates of theft might lead to increased punishment rates, for instance. This would bias upward the absolute value of the OLS parameter estimate, since the causal association of high punishment rates with low rates of theft would be offset by a reverse-causal association of high punishment rates with high rates of theft. Similar considerations might apply to $\log$ (SIZE): high rates of theft could lead to smaller-sized cooperatives, especially if members realize that a large organization is prone to free-riding and are more likely to form breakaway organizations. A variable that may be endogenous for different reasons is DRIP: members who expect to steal their water will have weaker incentives to adopt water-saving technologies. This would bias upward the OLS parameter estimate, since a causal association of high adoption of drip technology with low 
rates of theft would be reinforced by a reverse-causal association of high rates of theft with low rates of technology adoption.

To explore these possibilities our instrumenting strategy is as follows. Beginning with PUNISHMENT RATE, we use the idea that personal characteristics of the cooperative society managers may lead them to be more likely to inflict harsher punishments, and supplement these with geographical characteristics of the localities that may make harsher punishments more or less costly to inflict. Our relevant personal characteristics are captured by the variable EDUCATION. Our use of this variable is inspired by earlier evidence collected by one of us that education plays an important role in helping individuals to understand the importance of incentives and devise institutional responses to incentive problems. Seabright (1997) reports evidence from milk producers' cooperative societies in South India that more educated managers are more likely to use incentive-based methods to deter cheating by society members. For the geographical characteristics we use DENSITY: the idea is that higher population density may increase the costs in social discord of inflicting punishments, both because people depend more intensely on the land and because the punishers and the punished have to live more closely together. It is possible, however, that DENSITY also proxies for ease of monitoring and may therefore affect theft directly and not just via PUNISHMENT RATE; we test for this below and find the exclusion restriction justified. Finally, we use WATER SOURCE as an instrument since it seems likely that larger sources of water make it easier to exclude individuals who steal, since there are more third parties likely to be affected and therefore more pressure to sanction those who steal water. As an instrument for $\log (\mathrm{SIZE})$ we use an additional geographical variable which is HILLY AREA - in areas that are hilly the size of the cooperative is more likely to be limited by topographical constraints. 
Finally, as instruments for DRIP we use one geographical and two climatic variables that influence the productivity of the technology and two variables that capture the ability of farmers to afford the necessary investment. RED SOILS are those with lower water retention on which drip technology therefore saves more water. RAINFALL and ADVERSE CLIMATE ${ }^{24}$ capture respectively the relative abundance and scarcity of water to the cooperative. ALTERNATIVE REVENUE captures the greater economic ability of the farmers concerned to afford the investments in the drip technology, while PREVIOUS SPRINKLER captures the farmers' awareness of the benefits of water-saving technologies.

A word of caution is in order. Although we find the exclusion restrictions plausible we cannot rule out a priory that the proposed instruments do in fact affect theft directly, so we pay particular attention to the statistical tests of overidentifying restrictions that we report in all the instrumental variables specifications below.

Table 3 reports the results of these instrumental variables estimations. We instrument first for PUNISHMENT RATE, then for PUNISHMENT RATE and DRIP, and finally for both of these variables as well as for $\log (\mathrm{SIZE})$. In the final equation we replace EDUCATION (which may not be quite appropriate as an instrument for $\log (\mathrm{SIZE})$ since larger cooperatives are more likely to have educated individuals to call upon meaning that the proportion of educated farmers in the team of cooperative members in charge of running the cooperative's affairs is likely to increase) by the distance of the cooperative from the nearest large city ${ }^{25}$ which is a more clearly exogenous variable, and which is a significant predictor of education. Results provide a striking confirmation of our hypotheses about the determinants of theft, even when we control for the endogeneity of institutional rules and technology adoption. All the variables that were significant in our OLS specification remain significant in the 2SLS specification at $5 \%$ at least and in most cases at $1 \%$. 
They also show that our concerns about endogeneity are justified, though more for some variables than for others. The coefficient on PUNISHMENT RATE more than doubles in absolute magnitude compared to the OLS specification, suggesting that there is indeed a reverse causality effect of theft that tends to increase punishment rates. The Durbin-Wu-Hausman tests reject exogeneity of PUNISHMENT RATE at less than 5\% significance. The coefficient on DRIP falls a bit in absolute magnitude, confirming our conjecture that the OLS estimate is biased away from zero. A Durbin-Wu-Hausman test on this variable alone (not reported) rejects exogeneity at around 33\% significance. The coefficient on SIZE, however, does not change in a consistent way - the effect of instrumenting relative to OLS depends on the specification in question, and the coefficient does not change very much. Indeed a Durbin-Wu-Hausman test on this variable alone (not reported) fails to reject exogeneity at anything close to conventional significance levels, although the joint test of the exogeneity of all three variables is clearly rejected. It is also worth noting that the coefficient on PRICE increases when we instrument for the other variables, suggesting that the impact of PRICE on theft is even stronger before institutional responses act in mitigation.

The rest of the variables have the expected signs and are significant at a $5 \%$ or better level of confidence. The coefficient on DISTANCE is positive, because it reduces the expected level of monitoring, increasing thereby the scope for theft. The coefficient on REVENUE SHOCK is negative as expected. We are not sure how to interpret the positive coefficient on AGE (as we show below, AGE is significantly associated with higher punishment rates, which themselves reduce theft). It may indicate that the older are the cooperative managers ${ }^{26}$, the less inclined they are personally to monitor the other members (preferring to rely instead on more stringent punishment) to reduce their incentives of theft. This is in line with the findings of Niels Hermes, et al (2000) who report evidence that peer-monitoring by group leaders helps to reduce cheating by borrowers and increase 
their repayment performance. Similarly it is not clear how to interpret the negative coefficient on EQUIPPED SURFACE. This variable may well be associated with the wealth of the region where the cooperative is located, which will tend to be positively associated with the productivity of investment by the Water Authority in the region concerned. If so it may be negatively associated with liquidity constraints, and thereby be associated with lower incentives of theft.

Finally, the instruments comfortably pass the Hansen test of overidentifying restrictions. Interestingly, our exploration of the link between EDUCATION and institutional rules has an important and intuitive interpretation whose importance goes far beyond this particular context (and is supported by the work reported in Seabright, 1997 to which we referred above). This is that education has a powerful effect on the choice of institutions, in a direction that tends to reduce theft, but has no direct effect on theft apart from this.

\subsubsection{Institutional characteristics}

In this section we report the determinants of institutional characteristics, notably the punishment rate and the cooperative size.

Endogenous punishment Here we report the results of our estimates of the determinants of the PUNISHMENT RATE. The independent variables we use are the three discussed above, plus two controls:

Personal characteristics

- EDUCATION.

Physical characteristics affecting the ease of inflicting punishment:

- DENSITY. 
- WATER SOURCE.

Control Variables:

- AGE.

- DISTANCE.

Table 4 reports two OLS (Equations 4.1 and 4.2) and a 2SLS (Equation 4.3) estimation regressions with clustering on cooperatives. In Equation 4.1, we use just the first four variables. In Equation 4.2, we add the control for DISTANCE. The purpose of controlling for DISTANCE is twofold. First, it is to see whether monitoring costs are directly influencing the choice of punishment; the answer is that they are not. Secondly, it is to see whether its inclusion changes the coefficient on DENSITY, which might indicate that the latter is in fact proxying for monitoring costs and may therefore have a direct impact on theft. In fact DISTANCE is insignificant in the second equation and its inclusion leaves the coefficient on DENSITY almost unchanged; this increases our confidence in its validity as an instrument in the theft equations reported above, as well as in the conclusion that monitoring costs do not directly affect the choice of punishment rate. The negative coefficient on DENSITY may well indicate that monitoring costs do increase the required level of punishment. The latter is responding instead to factors that affect the cost of inflicting punishment, as well as to the ability of cooperative managers to understand the significance of incentives in the effective running of the organization.

AGE is indeed significant and has a positive coefficient. One plausible interpretation for the coefficient's sign is that older cooperative managers' are likely to be more experienced in the use of incentives. It may also indicate that they are less inclined to perform monitoring themselves as explained in the previous section. 
We also undertook a two-stage least squares estimation (Eq.4.3) with clustering on cooperatives, instrumenting EDUCATION with DISTANCE TO LARGE CITY but this did not change the coefficient $^{27}$ significantly.

Cooperative size We report here the results for the determinants of $\log (\mathrm{SIZE})$. Once again we use an approach based on both personal characteristics and geographical characteristics. We use the same variables as for PUNISHMENT RATE, plus two additional geographical variables that are likely to be particularly relevant to the determination of cooperative size. The first is ALTERNATIVE SOURCE, which measures the proportion of farmers who have access to water sources that are not controlled by the Water Authority (this is likely to reduce cooperative size for any given population since it decreases the incentive for farmers to join the cooperative). The second is HILLY AREA which is likely to have a negative effect on cooperative size by reducing the populated area in a given community. We expect WATER SOURCE to have a positive coefficient since larger sources make it easier to support more cooperative members.

As with PUNISHMENT RATE we shall also try to see whether DISTANCE is a significant regressor. Unlike in the case of PUNISHMENT RATE there are some reasons to fear that EDUCATION may be endogenous, since it is likely that larger cooperatives will have more educated members to call upon in the management of the cooperative. This would tend to bias downward the OLS parameter estimate (since a negative causal link would be offset by a positive reverse-causal link). We therefore try endogenizing EDUCATION using DISTANCE TO LARGE CITY as an instrument.

This leaves us with the following variables in the main equation:

- ALTERNATIVE SOURCE. 
- EDUCATION.

- DENSITY.

- DISTANCE.

- HILLY AREA.

- WATER SOURCE.

Table 5 (which illustrates two OLS and a 2SLS estimation regressions with clustering on cooperatives) shows our results.The findings are consistent with those for PUNISHMENT RATE. EDUCATION has an important influence on cooperative size, in the expected direction which is that more educated members choose smaller cooperatives (in the sense that more educated individuals may understand better the use of incentives and adapt cooperative rules to make theft more difficult). This finding is strengthened when we instrument for EDUCATION, since there is an effect of reverse causality making larger cooperatives contain more educated members. Instrumenting increases the absolute magnitude of the coefficient on EDUCATION by more than one half, a difference that is significant at under $5 \%$.

Once again DISTANCE is insignificant and makes no difference to the coefficients on the other explanatory variables, including DENSITY. This implies that cooperative size is not influenced directly by monitoring costs, but rather by the various geographical constraints that directly influence the costs and benefits of size, with more educated managers of the society appreciating the benefits of smaller size in terms of theft reduction. The insignificance of DISTANCE and its lack of correlation with DENSITY also strengthens our confidence in the exclusion restrictions in the theft equations in Table 3. 
Conclusions on institutional characteristics The results of these three exercises on the determinants of PUNISHMENT RATE, Log(SIZE) and DRIP can be summarized as follows:

The choice of PUNISHMENT RATE and Log(SIZE) do seem to be influenced by geographical factors which affect the costs and benefits of making these respective choices. DENSITY makes punishment more difficult and larger cooperatives easier. These choices are also clearly influenced by the education levels of the farmers who run the cooperatives. The latter appear to be aware of the importance of their choices for effective cooperative management, and more educated people makes these choices in ways that tend to reduce theft. We have found, however, no direct evidence that high monitoring costs in themselves lead to theft-reducing choices of these institutional variables. This may of course be due to the fact that DISTANCE is a very imperfect proxy for monitoring costs. We have considered whether our variable DENSITY could in fact be proxying for monitoring costs, which would suggest a role for such costs in both the choices of PUNISHMENT RATE and $\log (\mathrm{SIZE})$. However, the results of our regressions on the determinants of water theft show that DENSITY is insignificant in all specifications, which is inconsistent with the hypothesis that this variable is an alternative proxy for monitoring costs. We are left to conclude, then, that while monitoring costs directly various institutional innovations can counteract.

\section{Conclusion}

This paper has investigated how cooperative members choose their institutional rules, in terms of the cooperative size and the level of punishment inflicted on cheating farmers who are caught stealing. Thereafter, we show how the institutional rules and formal incentives affect farmers' decisions in terms of water theft. Based on survey data from irrigation cooperatives in five governorates in the north of Tunisia, the econometric evidence supports the findings of the theoretical models in 
that the size of the cooperatives and the levels of punishment inflicted on members caught stealing respond to the perceived costs and benefits of such choices. We also find support for the role of higher cooperative size in increasing the incentives for theft and of a higher level of punishment in reducing them. Moreover, the econometric evidence lends credence to the fact that monitoring costs and the price of water increase theft and drip-irrigation technology in turn reduces it.

Overall, these results provide strong confirmation of the ability of well designed incentives to reduce theft, as well as of the fact that institutions are not just exogenously given features of the social environment but adapt to the perceived costs and benefits of designing them in particular ways. They also show that higher monitoring costs have a positive effect on the incidence of theft, though one that various institutional innovations can counteract. 


\section{APPENDIX}

\section{A. The proof of proposition 1}

Before solving the game, let us show how the cooperative fine is distributed between members. In the absence of monitoring, cooperative members would share the fine equally. By monitoring each other, members reallocate the burden of the fine between themselves. Denote by $s_{i}^{\exp }\left(a_{i}, m_{i} ; a_{j}, m_{j}\right)$ the farmer $i$ 's expected share of such a fine, where $a_{k}=\left(q_{k}-q_{k}^{r}\right)$ is the amount of water stolen by farmer $k$, for $k=i, j$. In what follows we will focus only on symmetric equilibria. Suppose that both farmers steal, i.e., $a_{k}>0$. The expected share ${ }^{28}$ of farmer $i$ is lowered by the likelihood of discovering her peer cheating, and is in turn increased by the likelihood that she herself is discovered stealing by her peer.

$$
s_{i}^{\exp }=\frac{1}{2}\left(1-\kappa m_{i} a_{j}+\kappa m_{j} a_{i}\right)
$$

The subgame perfect equilibrium for this case corresponds to the profile $\left(m_{1}^{c}, m_{2}^{c}, q_{1}^{c}, q_{2}^{c}, q_{1}^{r c}, q_{2}^{r c}\right)$ of monitoring efforts $m_{i}^{c} \in[0,+\infty)$, water use levels $q_{i}^{c}:[0,+\infty)^{2} \rightarrow[0,+\infty)$ mapping from the set

of monitoring decisions into the set of water use decisions and water reports ${ }^{29} q_{i}^{r c}:[0,+\infty)^{2} \rightarrow\left[0, q_{i}\right]$ mapping from the set of monitoring decisions into the set of reports. The objective function of farmer $i$ is thus given by

$$
U_{i}\left(m_{i}, q_{i}, q_{i}^{r}\right)=g\left(q_{i}\right)-c q_{i}-t q_{i}^{r}-\frac{1}{2} f\left\{\begin{array}{c}
\left(1-\kappa m_{i}\left(q_{j}-q_{j}^{r}\right)+\kappa m_{j}\left(q_{i}-q_{i}^{r}\right)\right) \\
\left(\left(q_{i}-q_{i}^{r}\right)+\left(q_{j}-q_{j}^{r}\right)\right)
\end{array}\right\}-\psi\left(m_{i}\right)
$$

We solve the game by backward induction. At stage 2 of the game, farmer $i$ optimally chooses the amount of water to use, $q_{i}^{c} \equiv q_{i}^{c}\left(m_{i}, m_{j}\right)$ and the report to file, $q_{i}^{r c} \equiv q_{i}^{r c}\left(m_{i}, m_{j}\right)$ which maximize 
her expected payoff, given the levels of monitoring performed by the two members, $m_{i}$ and $m_{j}$ and that farmer $j$ chooses $q_{j}^{c} \equiv q_{j}^{c}\left(m_{i}, m_{j}\right)$ and $q_{j}^{r c} \equiv q_{j}^{r c}\left(m_{i}, m_{j}\right)$

$$
\max _{\left(q_{i}, q_{i}^{r}\right)} U_{i}\left(m_{i}, q_{i}, q_{i}^{r}\right)
$$

The first-order conditions with respect to $q_{i}$ and $q_{i}^{r}$ are respectively given by

$$
q_{i}^{c}: g^{\prime}\left(q_{i}\right)-c-\frac{1}{2} \kappa m_{j} f\left(\sum_{k=i, j}\left(q_{k}-q_{k}^{r}\right)\right)-\frac{1}{2} f\left(1-\kappa m_{i}\left(q_{j}-q_{j}^{r}\right)+\kappa m_{j}\left(q_{i}-q_{i}^{r}\right)\right)=0
$$

and

$$
q_{i}^{r c}:-t+\frac{1}{2} \kappa m_{j} f\left(\sum_{k=i, j}\left(q_{k}-q_{k}^{r}\right)\right)+\frac{1}{2} f\left(1-\kappa m_{i}\left(q_{j}-q_{j}^{r}\right)+\kappa m_{j}\left(q_{i}-q_{i}^{r}\right)\right)=0
$$

Rewriting equation (A4) gives the price of water $t$

$$
t=\frac{1}{2} \kappa m_{j} f\left(\sum_{k=i, j}\left(q_{k}-q_{k}^{r}\right)\right)+\frac{1}{2} f\left(1-\kappa m_{i}\left(q_{j}-q_{j}^{r}\right)+\kappa m_{j}\left(q_{i}-q_{i}^{r}\right)\right)
$$

Replacing the expression $\left\{\frac{1}{2} \kappa m_{j} f\left(\sum_{k=i, j}\left(q_{k}-q_{k}^{r}\right)\right)+\frac{1}{2} f\left(1-\kappa m_{i}\left(q_{j}-q_{j}^{r}\right)+\kappa m_{j}\left(q_{i}-q_{i}^{r}\right)\right)\right\}$ by $t$ (as shown by equation (A5)) into equation (A3) yields

$$
g^{\prime}\left(q_{i}\right)=c+t
$$

meaning that the amount of water used by farmer $i$ is independent of monitoring and punishment 
levels. The objective function $U_{i}(.,$.$) is strictly concave since its Hessian matrix$

$$
\mathbf{D}^{2} \mathbf{U}_{i}\left(\mathbf{q}_{i}, \mathbf{q}_{i}^{r}\right)=\left(\begin{array}{cc}
\mathrm{g}^{\prime \prime}\left(\mathbf{q}_{\mathbf{i}}\right)-\kappa \mathrm{fm}_{\mathbf{j}} & \kappa \mathrm{fm}_{\mathbf{j}} \\
\kappa \mathrm{fm}_{\mathbf{j}} & -\kappa \mathrm{fm}_{\mathbf{j}}
\end{array}\right)
$$

is negative definite (Since its first and second principal minors are negative and positive respectively). Therefore, the first-order conditions are both necessary and sufficient to identify a global maximum.

To simplify our calculations in the remainder of this proof, we will replace in equations (A3) and (A4) the amount of water stolen by farmer $k$, notably $\left(q_{k}-q_{k}^{r}\right)$ by $a_{k}$ for $k=i, j$.

$$
q_{i}^{c}: g^{\prime}\left(q_{i}\right)-c-\frac{1}{2} \kappa m_{j} f \sum_{k=i, j} a_{k}-\frac{1}{2} f\left(1-\kappa m_{i} a_{j}+\kappa m_{j} a_{i}\right)=0
$$

and

$$
q_{i}^{r c}:-t+\frac{1}{2} \kappa m_{j} f \sum_{k=i, j} a_{k}+\frac{1}{2} f\left(1-\kappa m_{i} a_{j}+\kappa m_{j} a_{i}\right)=0 .
$$

At stage 1 of the game, farmer $i$ chooses the monitoring effort, $m_{i}^{c}$ (given that farmer $j$ chooses $\left.m_{j}^{c}\right)$ so as to solve

$$
\max _{m_{i}} g\left(q_{i}\right)-c q_{i}-t q_{i}^{r}-\frac{1}{2} f\left(1-\kappa m_{i} a_{j}+\kappa m_{j} a_{i}\right)\left(a_{i}+a_{j}\right)-\psi\left(m_{i}\right) \text { for } i \neq j .
$$


whose first-order condition

$$
\frac{\partial U_{i}^{c}}{\partial m_{i}}=\left\{\begin{array}{c}
\left(g^{\prime}\left(q_{i}\right)-c-\frac{1}{2} \kappa m_{j} f \sum_{k=i, j} a_{k}-\frac{1}{2} f\left(1-\kappa m_{i} a_{j}+\kappa m_{j} a_{i}\right)\right) \frac{\partial q_{i}}{\partial m_{i}} \\
+\left(-t+\frac{1}{2} \kappa m_{j} f \sum_{k=i, j} a_{k}+\frac{1}{2} f\left(1-\kappa m_{i} a_{j}+\kappa m_{j} a_{i}\right)\right) \frac{\partial q_{i}^{r}}{\partial m_{i}} \\
+\frac{1}{2} \kappa f\left(a_{i}+a_{j}\right)\left(a_{j}+m_{i} \frac{\partial a_{j}}{\partial m_{i}}\right) \\
-\frac{1}{2} f\left(1-\kappa m_{i} a_{j}+\kappa m_{j} a_{i}\right) \frac{\partial a_{j}}{\partial m_{i}}-\psi^{\prime}\left(m_{i}\right)
\end{array}\right\} .
$$

It follows from equations $\left(\mathrm{A}^{\prime} 3\right)$ and $\left(\mathrm{A}^{\prime} 4\right)$, that the two expressions below are equal to zero

$$
\left\{g^{\prime}\left(q_{i}\right)-c-\frac{1}{2} \kappa m_{j} f \sum_{k=i, j} a_{k}-\frac{1}{2} f\left(1-\kappa m_{i} a_{j}+\kappa m_{j} a_{i}\right)\right\}=0
$$

and

$$
\left\{-t+\frac{1}{2} \kappa m_{j} f \sum_{k=i, j} a_{k}+\frac{1}{2} f\left(1-\kappa m_{i} a_{j}+\kappa m_{j} a_{i}\right)\right\}=0 .
$$

This reduces (A8) to the following expression

$$
\frac{\partial U_{i}^{c}}{\partial m_{i}}=\frac{1}{2} \kappa f\left(a_{i}+a_{j}\right)\left(a_{j}+m_{i} \frac{\partial a_{j}}{\partial m_{i}}\right)-\frac{1}{2} f\left(1-\kappa m_{i} a_{j}+\kappa m_{j} a_{i}\right) \frac{\partial a_{j}}{\partial m_{i}}-\psi^{\prime}\left(m_{i}\right)
$$

Given that the problem is symmetric for player $j$, the first-order condition with respect to the report filed by this former immediately follows from equation $\left(\mathrm{A}^{\prime} 4\right)$ above

$$
q_{j}^{r c}:-t+\frac{1}{2} \kappa m_{i} f \sum_{k=i, j} a_{k}+\frac{1}{2} f\left(1-\kappa m_{j} a_{i}+\kappa m_{i} a_{j}\right)=0 .
$$

Rewriting and rearranging equations $\left(\mathrm{A}^{\prime} 4\right)$ and (A10) yields the following system of two equations as functions of the levels of water stolen by the two cooperative members, notably $a_{i}$ and 
$a_{j}$

$$
\left\{\begin{array}{c}
2 \kappa m_{j} a_{i}+\left(\kappa m_{j}-\kappa m_{i}\right) a_{j}=\frac{2 t-f}{f} \\
\left(\kappa m_{i}-\kappa m_{j}\right) a_{i}+2 \kappa m_{i} a_{j}=\frac{2 t-f}{f}
\end{array},\right.
$$

Solving system (A11) gives the respective amounts of water stolen by farmers $i$ and $j$ as functions of their respective levels of monitoring $m_{i}$ and $m_{j}$

$$
a_{i}=\left(\frac{2 t-f}{\kappa f}\right) \frac{\left(3 m_{i}-m_{j}\right)}{\left(m_{i}+m_{j}\right)^{2}}
$$

and

$$
a_{j}=\left(\frac{2 t-f}{\kappa f}\right) \frac{\left(3 m_{j}-m_{i}\right)}{\left(m_{i}+m_{j}\right)^{2}}
$$

Differentiating (A13) with respect to cooperative members monitoring efforts $m_{i}$ and $m_{j}$ respectively, gives

$$
\frac{\partial a_{j}}{\partial m_{i}}=\left(\frac{2 t-f}{\kappa f}\right) \frac{\left(m_{i}-7 m_{j}\right)}{\left(m_{i}+m_{j}\right)^{3}}
$$

and

$$
\frac{\partial a_{j}}{\partial m_{j}}=\left(\frac{2 t-f}{\kappa f}\right) \frac{\left(5 m_{i}-3 m_{j}\right)}{\left(m_{i}+m_{j}\right)^{3}} .
$$

Differentiating (A14) with respect to the monitoring effort performed by farmer $i$, notably $m_{i}$ yields

$$
\frac{\partial^{2} a_{j}}{\partial m_{i}^{2}}=\left(\frac{2 t-f}{\kappa f}\right) \frac{\left(-2 m_{i}+22 m_{j}\right)}{\left(m_{i}+m_{j}\right)^{4}}
$$

Since we look only at the symmetric subgame perfect equilibrium, then the equilibrium level 
of theft is $a_{i}^{c}=a_{j}^{c} \equiv a^{c}$ and the equilibrium monitoring effort is $m_{i}^{c}=m_{j}^{c} \equiv m^{c}$ and they are respectively given by:

$$
a^{c}=\frac{(2 t-f)}{2 \kappa m^{c} f},
$$

and

$$
m^{c}: \frac{(2 t-f)(2 f-t)}{4 \kappa f m^{2}}=\psi^{\prime}(m)
$$

Depending on the stringency of the punishment rate, $f$ two cases arise:

Case 1: If the punishment rate is stringent enough, i.e., when $f \geq 2 t$

The equilibrium amount of water stolen for a given level of monitoring will be non positive, i.e.,

$$
a^{c}=\frac{(2 t-f)}{2 \kappa m^{c} f} \leq 0,
$$

meaning that farmers may well over-report, i.e., $a^{c}<0$. However, since there are no rewards for over-reporting (by assumption), farmers will never gain by doing so. This implies that theft does not occur in equilibrium

$$
a^{c}=0
$$

Plugging Eq. (A17) into Eq. (A18), yields the equilibrium intensity of monitoring which is implicitly given by 


$$
\frac{(2 f-t)}{2} a^{c}=m^{c} \psi^{\prime}\left(m^{c}\right) .
$$

Using the fact that theft does not occur in equilibrium and the fact that $\psi^{\prime}(0)=0$, yields that farmers do not monitor in equilibrium

$$
m^{c}=0 .
$$

Case 2: If the punishment rate is less stringent than in the previous case, but exceeds the price of water, i.e., when $t<f<2 t$

Now let us check whether the first-order condition for the level of monitoring $m^{c}$ given by (A18) is sufficient. Differentiating (A9) with respect to $m_{i}$ gives

$$
\frac{\partial^{2} U_{i}}{\partial^{2} m_{i}^{2}}=\left\{\begin{array}{c}
\frac{1}{2} \kappa f\left(\left(2 \frac{\partial a_{j}}{\partial m_{i}}+m_{i} \frac{\partial^{2} a_{j}}{\partial m_{i}^{2}}\right)\left(a_{i}+a_{j}\right)+\left(a_{j}+m_{i} \frac{\partial a_{j}}{\partial m_{i}}\right)\left(\frac{\partial a_{i}}{\partial m_{i}}+\frac{\partial a_{j}}{\partial m_{i}}\right)\right) \\
+\frac{1}{2} f\left(\kappa\left(a_{j}+m_{i} \frac{\partial a_{j}}{\partial m_{i}}-m_{j} \frac{\partial a_{i}}{\partial m_{i}}\right) \frac{\partial a_{j}}{\partial m_{i}}-\left(1-\kappa m_{i} a_{j}+\kappa m_{j} a_{i}\right) \frac{\partial^{2} a_{j}}{\partial m_{i}^{2}}\right)-\psi^{\prime \prime}\left(m_{i}\right)
\end{array}\right\}
$$

Replacing $a_{k}$ and $m_{k}$ by the equilibrium levels of theft and monitoring respectively $a^{c}$ and $m^{c}$ for $k=i, j$ yields that the second partial derivative of the farmer's utility function is strictly negative.

$$
\frac{\partial^{2} U_{i}}{\partial m_{i}^{2}}\left(m^{c}, a^{c}\right)=\left(\frac{2 t-f}{\kappa f}\right)\left(\frac{t-3 f}{4\left(m^{c}\right)^{3}}\right)-\psi^{\prime \prime}\left(m^{c}\right)<0
$$

This means that the first-order condition for the monitoring level is necessary and also sufficient to identify a global maximum. This completes the proof of proposition 1 .

\section{B. Centralized water management}

We assume that under centralized management the WA can commit, before farmers choose their 
actual and reported levels of water use, to a level $m$ of monitoring its members' activities, at a cost $\Psi(m)$, which is increasing and convex ${ }^{30}$. We assume that monitoring cannot be conditioned on the farmer's report and must be the same for all reports. The probability that a farmer is discovered stealing $^{31}$ is given by

$$
P(m, a)=\min \{\kappa m \max \{a, 0\}, 1\}
$$

When the farmer is detected stealing, her true intake is established without error and she pays $t q^{r}$ plus a penalty proportional to the amount of water stolen, $F^{c s}$ (the solution to this scheme will be indexed with the superscript "cs"). It is the nature of the monitoring system which makes it possible to use a punishment device based on individual levels of theft. The punishment is measured in terms of the length of time for which water is cut off from a cheating member. This length is proportional to the farmer's level of theft. The punishment is assumed to take the form:

$$
F^{c s}=f \max \{a, 0\}
$$

where the punishment rate $f$ is positive, greater than $t$ (Because otherwise farmers will have an interest in stealing everything, see footnote 11).

The order of events is that the WA sets $m$, and $t$, then each farmer chooses the quantity of water to use $q^{c s}$ and the report to file $q^{r c s}$. In what follows we focus on the subgame perfect equilibrium and solve the model by backward induction. In stage 2 of the game, the farmer chooses $q^{c s}$ and $q^{r c s}$ in order to maximize her expected payoff, i.e.,

$$
\max _{\left(q, q^{r}\right)} U^{c s}\left(q, q^{r}\right)=g(q)-c q-t q^{r}-\kappa m f\left(q-q^{r}\right)^{2} .
$$

Whose first-order conditions with respect to $q$ and $q^{r}$ are respectively given by 


$$
q^{c s}: g^{\prime}\left(q^{c s}\right)=c+2 \kappa m f\left(q^{c s}-q^{r c s}\right)
$$

and

$$
q^{r c s}: t=2 \kappa m f\left(q^{c s}-q^{r c s}\right)
$$

Eq.(B4) into Eq.(B5) implies that $q^{c s}$ is independent of $m$ and $f$

$$
g^{\prime}\left(q^{c s}\right)=c+t
$$

Now we turn to the initial contracting stage, where the WA anticipates the farmer's behavior and picks a monitoring effort ${ }^{32} m$ and a price of water $t$ that maximize the social benefit. Specifically this benefit function is the sum of the farmers' surpluses $2\left(g\left(q^{c s}\right)-(c+t) q^{c s}-\kappa m f\left(q^{c s}-q^{r c s}\right)^{2}\right)$ and the water supplier surplus equal to the revenue from water proceeds $2 t q^{r c s}$, from which is deduced the cost of water provision to $2 \gamma q^{c s}$ and the cost incurred by monitoring $2 \Psi(m)$

$$
W^{c s}(m, t)=2\left(g\left(q^{c s}\right)-(c+\gamma) q^{c s}-\kappa m f\left(q^{c s}-q^{r c s}\right)^{2}-\Psi(m)\right) .
$$

We can then show:

PROPOSITION 2: The optimal monitoring and pricing policy used by the WA $\left\{m^{c s}, t^{c s}\right\}$ satisfies

$$
\begin{gathered}
m^{c s}: \frac{\left(t^{c s}\right)^{2}}{4 \kappa\left(m^{c s}\right)^{2} f}=\Psi^{\prime}\left(m^{c s}\right), \\
t^{c s}=\gamma\left(\frac{2 \kappa m^{c s} f}{2 \kappa m^{c s} f-g^{\prime \prime}\left(q^{c s}\right)}\right),
\end{gathered}
$$

and yields a level of theft by each farmer given by 


$$
a^{c s}=\frac{t^{c s}}{2 \kappa f m^{c s}}
$$

Proof: (See below after the interpretation of the proposition).

The proposition says that some level of monitoring is always required in equilibrium. However, because monitoring is costly, the optimal response of the WA is to tolerate some theft in order to save in monitoring costs. Moreover, in the presence of theft, the optimal second-best price of water is typically lower than in its absence, i.e., $t^{c s}<\gamma$ : it is worth tolerating some allocative inefficiency in water use in return for a reduction of theft occurrence.

How feasible it is for the authority to charge below $\gamma$ for its water will depend on circumstances and in particular the extent to which it is constrained to avoid making losses. In the presence of theft, the authority would make losses in any case if it charged at marginal cost, since this would imply a positive level of theft and therefore an average revenue well below marginal and average cost. If the authority were able to pursue the goal of maximizing social welfare it could set a price that balanced the need to raise revenue with the need to diminish incentives for theft, as we have described; otherwise it might take explicit account of the shadow price of public funds. We have not pursued these complications here and do not believe they would fundamentally affect the qualitative nature of our calculations.

\section{The proof of proposition 2}

At the initial contracting stage, the WA picks the monitoring level, $m$ and the price of water, $t$ which maximize the following social welfare function

$$
\max _{(m, t)} W^{c s}(m, t)=2\left(g\left(q^{c s}\right)-(c+\gamma) q^{c s}-\kappa m f\left(q^{c s}-q^{r c s}\right)^{2}-\Psi(m)\right)
$$


Whose first-order conditions are derived as follows:

1. First, we take the first partial derivative of the social welfare function, $W^{c s}(m, t)$ with respect to $m$

$$
\frac{\partial W^{c s}(m, t)}{\partial m}=2\left(\begin{array}{c}
\left(g^{\prime}\left(q^{c s}\right)-(c+\gamma)-2 \kappa m f\left(q^{c s}-q^{r c s}\right)\right) \frac{\partial q^{c s}}{\partial m} \\
+2 \kappa m f\left(q^{c s}-q^{r c s}\right) \frac{\partial q^{r c s}}{\partial m}-\kappa f\left(q^{c s}-q^{r c s}\right)^{2}-\Psi^{\prime}(m)
\end{array}\right)=0,
$$

We take the first partial derivatives of the farmer's water use and report levels, $q^{c s}$ and $q^{r c s}$ (given by equations (B4) and (B5) with respect to $m$

$$
\frac{\partial q^{c s}}{\partial m}=0 \text { and } \frac{\partial q^{r c s}}{\partial m}=\frac{1}{m}\left(q^{c s}-q^{r c s}\right)
$$

Replacing $\frac{\partial q^{c s}}{\partial m}$ and $\frac{\partial q^{r c s}}{\partial m}$ by their expressions into Eq.(B12) yields

$$
\frac{\partial W^{c s}(m, t)}{\partial m}=2\left(\kappa f\left(q^{c s}-q^{r c s}\right)^{2}-\Psi^{\prime}(m)\right)=0
$$

Moreover, plugging the expression of the level of theft $\left(q^{c s}-q^{r c s}\right)=\frac{t}{2 \kappa m f}$ into Eq. (B13) gives

$$
\frac{\partial W^{c s}(m, t)}{\partial m}=2\left(\frac{t^{2}}{4 \kappa f m^{2}}-\Psi^{\prime}(m)\right)=0
$$

Rearranging Eq.(B14) yields the equilibrium monitoring effort which is implicitly given by

$$
\frac{t^{2}}{4 \kappa f\left(m^{c s}\right)^{2}}=\Psi^{\prime}\left(m^{c s}\right)
$$


2. Second, we take the first partial derivative of $W^{c s}(m, t)$ with respect to $t$

$$
\frac{\partial W^{c s}(m, t)}{\partial t}=2\left\{\begin{array}{c}
\left(g^{\prime}\left(q^{c s}\right)-(c+\gamma)-2 \kappa m f\left(q^{c s}-q^{r c s}\right)\right) \frac{\partial q^{c s}}{\partial t} \\
+2 \kappa m f\left(q^{c s}-q^{r c s}\right) \frac{\partial q^{r c s}}{\partial t}
\end{array}\right\}=0
$$

Recall that $g^{\prime}\left(q^{c s}\right)$ and the first partial derivatives of the farmer's water use and report levels, $q^{c s}$ and $q^{r c s}$ with respect to $t$ are given by

$$
g^{\prime}\left(q^{c s}\right)=c+t ; \frac{\partial q^{c s}}{\partial t}=\frac{1}{g^{\prime \prime}\left(q^{c s}\right)} \text { and } \frac{\partial q^{r c s}}{\partial t}=\frac{1}{g^{\prime \prime}\left(q^{c s}\right)}-\frac{1}{2 \kappa m^{c s} f}
$$

Substituting $g^{\prime}\left(q^{c s}\right), \frac{\partial q^{c s}}{\partial t}$ and $\frac{\partial q^{r c s}}{\partial t}$ by their expressions above into (B17) yields

$$
\frac{\partial W^{c s}(m, t)}{\partial t}=2\left(\frac{(t-\gamma)}{g^{\prime \prime}\left(q^{c s}\right)}-\frac{t}{2 \kappa m^{c s} f}\right)=0
$$

Rearranging Eq. (B18) gives the equilibrium price of water

$$
t^{c s}=\gamma\left(\frac{2 \kappa m^{c s} f}{2 \kappa m^{c s} f-g^{\prime \prime}\left(q^{c s}\right)}\right)
$$

The objective function $W(.,$.$) is strictly concave since its Hessian matrix$

$$
\mathbf{D}^{2} \mathbf{W}(\mathbf{m}, \mathbf{t})=\left(\begin{array}{cc}
-\frac{\mathrm{t}^{2}}{\kappa \mathrm{fm}^{3}}-2 \Psi^{\prime \prime}(\mathbf{m}) & \frac{\mathrm{t}}{\kappa \mathrm{fm}^{2}} \\
\frac{\mathrm{t}}{\kappa \mathrm{fm}^{2}} & 2\left(\frac{1}{\mathrm{~g}^{\prime \prime}(\mathbf{q})}-\frac{1}{2 \kappa \mathrm{mf}}\right)
\end{array}\right)
$$

is negative definite for every $(m, t)$. The first and second principal minors are negative and positive respectively (i.e., $H_{1}=\left(-\frac{t^{2}}{\kappa f m^{3}}-2 \Psi^{\prime \prime}(m)\right)<0$ and $H_{2}=\operatorname{det} D^{2} W(m, t)-\frac{t^{2}}{\kappa f m^{3}} \frac{2}{g^{\prime \prime}(q)}-$ 
$4 \frac{\Psi^{\prime \prime}(m)}{g^{\prime \prime}(q)}+2 \Psi^{\prime \prime}(m) \frac{1}{\kappa m f}>0$.). Moreover, their signs are independent of where they are evaluated. The first-order conditions are both necessary and sufficient to identify a global maximum. This completes the proof of proposition 2. 


\section{ENDNOTES}

1 The notion of water theft here is distinct from that in the model of Azam and Rinaudo (2000). In their paper farmers who are located next to a water stream are allocated fixed quotas. The upstream farmer may well exceed her allocated quota, depriving the downstream farmer from part of her quota (meaning that the former steals water directly from the latter). However, in our model farmers do not steal water from each other but they instead do so directly from the Water Authority.

2 A paper by Asim (2001) argues that the influence of social capital on the performance of infrastructure projects has been overrated because different designs of projects can offset the impact of adverse social capital. Without wishing to take a stance on the relative importance of social capital and project design as explanations for different performance, our results support the idea that improved design of the structure and rules of projects (and related institutions) may compensate for otherwise adverse conditions.

3 The pollution is specifically said to be nonpoint if the polluters' individual emissions that generate this pollution are fully or partially unobservable by the regulator at a reasonable cost.

${ }^{4}$ To the best of our knowledge, ambient-based schemes have rarely been implemented in the field yet (an exception is presented in Ribaudo, Horan and Smith, 1999). This means that there are very few real data to assess the practical efficiency of the instrument. The experimental economics have overcome the obstacles inherent in the use of real world data by collecting data in a controlled environment, i.e., the laboratory.

${ }^{5}$ Since the total amount of water use by farmers is publicly known, this makes it like a moral hazard in teams - where the WA may discipline team members through monetary incentives that break the budget constraint, restoring thereby the full-information outcome (See Holmström, 1982). Such 
scheme works independently of group size, but may be infeasible when members have endowment constraints.

${ }^{6}$ What a member may observe is whether her peers manipulate their meters (besides the farmer herself, only the WA can have access to the former's meter and in case the meter has been indeed manipulated, the evidence about this fact will be established with certainty). However, this does not exclude the possibility that a member might infer her peers' true intakes, particularly for small communities where members know each other. This is less likely for large cooperatives.

${ }^{7}$ It is worth clarifying how peer-monitoring mechanism works in more details:

When a cooperative member is declared to be a cheater, the WA checks whether her water meter has been manipulated. A cooperative member may indeed make a monitoring mistake or also deliberately lie and declare her peer as cheater in order to shift the cooperative fine on her (or on others), but when checking the peer's meter and no evidence about her manipulation is established, this latter will not be considered as a cheater. In case all members are declared to have stolen by each other, the WA checks all members' meters and those for whom the evidence about manipulation has been established will be treated as cheaters and punished consequently. In the extreme case, where all members are not mistakenly declared to have stolen, they will split the total fine equally between them, since the evidence about their meters' manipulation will be established with certainty. Finally, in case no member is declared cheating, the WA does not need to check whether the cooperative members meters have been manipulated, the fine will automatically be shared equally between all members (even if cooperative members have colluded to make wrong declaration).

${ }^{8}$ One may think of observable sunk investments being made by cooperative members, and which would commit them to higher monitoring efforts. For instance, it is frequent in developing countries 
like Tunisia that landlords build little houses in their farms where they keep equipment for daily use and where both landlords and laborers may spend some time.

${ }^{9}$ We sidestep the issue of collusion here because it is not central to the paper's argument, and it is quite complicated analytically. Assuming that collusion in monitoring efforts is not possible may seem a strong assumption, especially if the cooperative represents a small community where all farmers know each other. However, this might be quite plausible for large cooperatives, or in smaller cooperatives where monitoring opportunities are relatively asymmetric (e.g. because people can observe their neighbors more easily than they can observe others).

10 The price of water $t$ is then exogenous to the cooperative mechanism (carried out at the farmers' level).

11 The punishment rate $f$ assumed to be greater than $t$, because otherwise the farmer will always have an interest in stealing everything. The net return of water theft is equal to $\left(t-\kappa m^{c} f a^{c}\right) a^{c}$, with the probability $\kappa m^{c} a^{c}<1$. If $f<t$, one gets $\kappa m^{c} a^{c} f<f<t$, and therefore theft is strictly beneficial; this essentially implies that the net return is maximized when the farmer steals everything.

12 The distributional effect is inferred from the proof of proposition 1 (in the appendix) which explains explicitly how peer-monitoring affects the distribution of the punishment burden between cooperative members. Hereinafter is the proof:

The expected share of farmer $i$ from the cooperative fine, denoted by $s_{i}^{\exp }\left(a_{i}, m_{i} ; a_{j}, m_{j}\right)$ is equal to

$$
s_{i}^{\exp }=\frac{1}{2}\left(1-\kappa m_{i} a_{j}+\kappa m_{j} a_{i}\right)
$$


where, $a_{i}$ and $a_{j}$ are the amount of water stolen by farmers $i$ and $j$ given respectively by

$$
a_{i}=\left(\frac{2 t-f}{\kappa f}\right) \frac{\left(3 m_{i}-m_{j}\right)}{\left(m_{i}+m_{j}\right)^{2}}
$$

and

$$
a_{j}=\left(\frac{2 t-f}{\kappa f}\right) \frac{\left(3 m_{j}-m_{i}\right)}{\left(m_{i}+m_{j}\right)^{2}}
$$

By differentiating the expected share of farmer $i$, with respect to the monitoring effort performed by her peer, farmer $j$, one gets

$$
\frac{\partial s_{i}^{\exp }\left(m_{i}, m_{j}\right)}{\partial m_{j}}=\frac{1}{2}\left[-\kappa m_{i} \frac{\partial a_{j}}{\partial m_{j}}+\kappa a_{i}+\kappa m_{j} \frac{\partial a_{i}}{\partial m_{j}}\right]
$$

Where, the partial derivatives of $a_{j}$ and $a_{i}$ with respect to $m_{j}$, notably $\frac{\partial a_{j}}{\partial m_{j}}$ and $\frac{\partial a_{i}}{\partial m_{j}}$ are respectively given by

$$
\frac{\partial a_{j}}{\partial m_{j}}=\left(\frac{2 t-f}{\kappa f}\right) \frac{\left(5 m_{i}-3 m_{j}\right)}{\left(m_{i}+m_{j}\right)^{3}}
$$

and

$$
\frac{\partial a_{i}}{\partial m_{j}}=\left(\frac{2 t-f}{\kappa f}\right)\left[\frac{3 m_{j}-5 m_{i}}{\left(m_{i}+m_{j}\right)^{3}}\right]
$$

Replacing $\frac{\partial a_{j}}{\partial m_{j}}$ and $\frac{\partial a_{i}}{\partial m_{j}}$ by their expressions given by equations (V) and (VI) into equation (IV) yields

$$
\frac{\partial s_{i}^{\exp }\left(m_{i}, m_{j}\right)}{\partial m_{j}}=\left(\frac{2 t-f}{f}\right) \frac{1}{\left(m_{i}+m_{j}\right)^{3}}\left(4 m_{i}^{2}+m_{j}^{2}\right)>0
$$

As one can see, the expected share of farmer $i$ from the cooperative fine increases with the 
monitoring effort performed by her peer, farmer $j$, meaning that this later monitors the former in order to shift the cooperative fine on her.

${ }^{13}$ Equations (7), (8) and (9) come from Eq.(6) and from the quadratic form of the monitoring cost $\psi(m)=\frac{1}{2} b m^{2}$ replacing the general monitoring cost function into Eq.(6). This yields the equilibrium monitoring effort

$$
m^{c}=\left(\frac{(2 t-f)(2 f-t)}{4 \kappa b f}\right)^{\frac{1}{3}}
$$

14 The monitoring effort is chosen in the first stage of the game, and is therefore a parameter in the second stage when the farmer chooses the amount of water to use and the report to file.

15 Equations (10), (11) and (12) come from Eq.(5) and from the quadratic form of monitoring cost function $\psi(m)=\frac{1}{2} b m^{2}$. Replacing the monitoring effort by

$$
m^{c}=\left(\frac{(2 t-f)(2 f-t)}{4 \kappa b f}\right)^{\frac{1}{3}}
$$

into Eq.(5) allows us to derive the comparative static results $\frac{\partial a^{c}}{\partial f}$ and $\frac{\partial a^{c}}{\partial t}$.

16 The explanation relates to the fact that the probability of catching a cheating member increases in her monitoring by others and in her own level of theft. When a farmer monitors her peer intensively she may reduce significantly her incentives for theft, reducing thereby the likelihood of detecting her stealing, and increasing the expected fine faced by the farmer as a result of her own equilibrium level of theft. This is like a "reverse business stealing" externality that lowers the farmer's monitoring below the (second-best) efficient level.

17 This is driven by the increased complexity and difficulty of enforcing stringent punishments on individuals from the same community.

${ }^{18}$ Differentiating the cooperative welfare function with respect to $f$ yields 


$$
\frac{d W^{c}}{d f}=2\left\{\left[g^{\prime}\left(q^{c}\right)-(c+\gamma)\right] \frac{\partial q^{c}}{\partial f}-a^{c}-f \frac{\partial a^{c}}{\partial f}-2 \frac{1}{2} b m^{c} \frac{\partial m^{c}}{\partial f}\right\}-\varphi^{\prime}(f)=0
$$

Taking into account that $q^{c}$ is independent of $f$ and replacing $a^{c}, \frac{\partial m^{c}}{\partial f}$ and $\frac{\partial a^{c}}{\partial f}$ by their expressions given respectively by equations (5), (9) and (11), we obtain the first-order condition corresponding to Eq.(17) in the text.

19 This follows from the strong convexity of the cost of inflicting punishment, which ensures the concavity of the objective function $W^{c}(f)$.

20 The intuition suggests that cooperative size affects monitoring in two ways. On one hand, a larger group discourages monitoring because of free-riding. On the other hand, a larger team may increase the total amount of theft in the cooperative increasing thereby the maximum punishment that would be incurred by a member who was the only one to be caught, increasing therefore the incentives for monitoring.

Due to the analytical complexity, we have examined these issues through a numerical example. Simulation results suggest that for plausible punishment levels (laying between $t$ and $2 t$ ), monitoring is decreasing in the cooperative size (meaning that the free-riding effect tends always to dominate).

${ }^{21}$ Farmers who have plots of land in the cooperative area decide to become members of the cooperative by signing membership contracts specifying that they will be provided water by the cooperative, pay a fixed fee for their membership and commit to participate in meetings decided by managers to discuss some of the cooperative's affairs when it is necessary.

${ }^{22}$ See the definition of WATER THEFT.

${ }^{23}$ We did not use a continuous variable here because we do not have the exact storage capacities of boreholes. 
${ }^{24}$ This captures a more general range of adverse climatic conditions than simple water scarcity, and which have been found by other researchers to be associated with technology adoption (see Koundouri, P. et al., 2006).

25 This is a plausible positive proxy for education infrastructure or/and for proximity to schools.

${ }^{26}$ We have mentioned above that the variable education suffers from endogeneity, and in equation 3.4 we instrument for it using a more exogenous variable, namely the distance of the cooperative to the nearest large city.

27 The manager' age might well be interpreted as a positive proxy for costs of monitoring performed by this former.

28 The positive coefficient on EDUCATION (as reported in table 4) is unlikely to be due to the fact that more educated individuals are richer and can afford to pay higher fines, since the punishment is measured in terms of the length of time for which water is cut off from a cheating member - a measure whose cost is increasing in the amount of land cultivated by the farmer concerned.

29 The expected share of farmer $i$ from the cooperative fine when everyone steals is given by

$$
\begin{aligned}
s_{i}^{\exp }= & \frac{1}{2}\left(\kappa m_{i} a_{j}\right)\left(\kappa m_{j} a_{i}\right)+\kappa m_{j} a_{i}\left(1-\kappa m_{i} a_{j}\right) \\
& +\frac{1}{2}\left(1-\kappa m_{i} a_{j}\right)\left(1-\kappa m_{j} a_{i}\right)
\end{aligned}
$$

Where the first term corresponds to her share when both farmers are caught stealing, the second term is her share when she is caught and farmer $j$ not, and the last term is her share when none is caught.

Rearranging the equation above gives the expression in (A1). 
30 The set of reports is reduced to $\left[0, q_{i}\right]$ because it is assumed throughout this paper that there are no rewards for over-reporting.

31 The cost of monitoring should be understood as including not only the wages of monitors, but other costs as measurement devices aiming at making water intakes observable.

32 Detecting a cheating farmer is based on detecting her meter's manipulation (which is not based on the amount recorded by the meter (the report), but rather on evidence(s) of manipulation observed on the meter or catching this farmer while manipulating her meter).

${ }^{33}$ The WA is able to control the punishment rate, $f$ in addition to controlling the monitoring and pricing decisions (when punishment is endogenous and costly, some level of punishment is always required in equilibrium. However, because punishment is costly, the optimal response of the WA is to tolerate some theft in order to save in punishment costs). 


\section{References}

[1] Alpizar, F., T. Requate, and A. Schram. 2004. "Collective versus Random Fining: An Experimental Study on Controlling Ambient Pollution" Environmental and Resource Economics 29:231-252.

[2] Armanderiz De Aghion, B. 1999. "On the Design of a Credit Agreement with Peer monitoring" Journal of Development Economics 60:79-104.

[3] Asim, I.K. 2009. "Can Good Projects Succeed in Bad Communities?" Journal of Public Economics 93(7):899-916.

[4] Azam, J.P., and J.D. Rinaudo. 2000. "Encroached Entitlements: Corruption and Appropriation of Irrigation water in Southern Punjab Pakistan" Centro Studi Luca d' Agliano Queen Elizabeth House Development Studies Working Papers (144):33pp.

[5] Besley, T., and S. Coate. 1995. "Group Lending, Repayment Incentives and Social Collateral" Journal of Development Economics 46:1-18.

[6] Cabe, R., and J. Herriges. 1992. "The Regulation of Nonpoint Source Pollution under Imperfect and Asymmetric Information" Journal of Environmental Economics and Management 22(2):134-146.

[7] Caswell, M., and D. Zilberman. 1985. "The Choices of Irrigation Technologies in California" American Agricultural Economics Association 67:224-234.

[8] Chander, P., and L.L. Wilde. 1998. "A General Characterization of Optimal Income Tax Enforcement" Review of Economic Studies 65:165-183. 
[9] Che, Y.K. 2002. "Joint Liability and Peer Monitoring under Group Lending" Working paper, Dept. of Econ., University of Wisconsin-Madison.

[10] Cochard, F., M. Willinger, and A. Xepapadeas. 2005. "Efficiency of Nonpoint Source Pollution Instruments: an Experimental Study" Environmental Resource Economics 29:231-252.

[11] Conning, J. 2005. "Monitoring by Delegates or by Peers? Joint Liability Loans under Moral Hazard" working paper, Dept. of Econ., Hunter college and the Graduate Center, City University of New York

[12] Cremer, H. et al. 1990. "Tax Evasion and Auditing" Journal of Public Economics 43:67-92.

[13] Ghatak, M., and T.W. Guinnane. 1999. "The Economics of Lending with Joint Liability: Theory and Practice" Journal of development economics 60:195-228.

[14] Feder, G., E.J. Richard, and D. Zilberman. 1985. "Adoption of Agricultural Innovations in Developing Countries: A survey" Economic Development and Cultural Change 33(2):255-298.

[15] Foltz, J.D. 2003. "The Economics of Water-conserving Technology Adoption in Tunisia: An Empirical Estimation of Farmer Technology Choice" Economic Development and Cultural Change 51(2):359-373

[16] Hansen, L.G. 1998. "A Damage Based Tax Mechanism for Regulation of Non-point Emissions" Environmental and Resource Economics 12:99-112.

[17] Herriges, J., A. Joseph, R. Govindasamy, and J.F. Shogren. 1994. "Budget-Balancing Incentive Mechanism" Journal of Environment Economics and Management 27:275-285. 
[18] Hermes, N., R. Lensink, and H.T. Mehrteab. 2005. "Peer monitoring, Social Ties and Moral Hazard in Group Lending Programmes: Evidence from Eritrea" World Development 331:149169.

[19] Awudu, A., T. Glauben, T. Herzfeld, and S. Zhou. 2005. "Water Saving Technology in Chinese Rice Production-evidence from Survey Data" Working paper no. 24708, European Association of Agricultural Economists.

[20] Holmström, B. 1982. "Moral Hazard in Teams" The Bell Journal of Economics 13:324-340.

[21] Johansson, R.C., Y. Tsur, T. Roe, R. Doukkali, and A. Dinar. 2002. "Pricing Irrigation Water: A Review of Theory and Practice" Water Policy 4:173-199.

[22] Kandel, E., and E.P., Lazear. 1992. "Peer Pressure and Partnerships" Journal of Political Economy 100(4):801-818.

[23] Karp, L. 2005. "Non point Source Pollution Taxes and Excessive Burden" Environmental and Resource Economics 31(2):229-251.

[24] Koundouri, P., C. Nauges, and V. Tzouvelekas. 2006. "Endogenous Technology Adoption under Production Risk: Theory and Application to Irrigation Technology" American Journal of Agricultural Economics, 88(3):345-369.

[25] Laffont, J.J. 2001. "Institutions, Regulation and Development" Distinguished lecture series 16.

[26] Laffont, J.J., and M.S., Matoussi. 1995. "Moral hazard, Financial Constraints and Sharecropping in El Oulja" Review of Economic Studies 62:381-399.

[27] Laffont, J.J., and J. Tirole. 1993. A Theory of Incentives in Procurement and Regulation, Cambridge: MIT Press. 
[28] Laffont, J., and J. Tirole. 1986. "Using Cost Information to Regulate Firms" Journal of Political Economy 95:921-937.

[29] Loehman, E., and A. Dinar. 1994. "Cooperative Solution of Local Externality Problems: A Case of Mechanism Design Applied to Irrigation" Journal of Environmental Economics and Management 26:235-256.

[30] Matoussi, M.S., and S. Slama. 1999. "Modélisation d'un Arbitrage Centralisé des Resources en Eau" Working paper, CRDI, Univerity of Tunis.

[31] Mattoussi, W., and P. Seabright. 2007. "On the Design of Irrigation Cooperatives with Peer monitoring" Working paper, INRA, Univerity of Toulouse.

[32] Mattoussi, W., and F. Mattoussi. 2013. "Adoption of Modern Irrigation Technologies in the Presence of Water Theft and Corruption: Evidence from Public Irrigated Areas in Medjez El Bab" Working paper, LAREQUAD, University of Jendouba.

[33] Mattoussi, W. 2006. "Cooperation Against Theft: Theory and Test of Incentives for Water Management in Tunisia." PhD dissertation, University of Toulouse.

[34] Merry, D.J. 1996. Institutional Design Principles for Accountability in Large Irrigation Systems. Research Report 8. Colombo, Sri Lanka: International Water Management Institute.

[35] Miceli, T., and K. Segerson. 1991. "Joint Liability in Torts and Infra-marginal Efficiency" International Revue of Law and Economics 11:235-249.

[36] Millock, K., and F. Salanié. 2005. "Nonpoint Source Pollution when Polluters might Cooperate" Topics in Economic Analysis 83 Policy 5(1), Article 12. 
[37] Moncur, J.E.T., and R.L. Pollack. 1988. "Scarcity Rents for Water: A Valuation and Pricing Model" Land Economics 64 (1):62-72.

[38] Poe, G.L., W.D. Schulze, K. Segerson, J.F. Suter, and C.A. Vossler. 2004. "Exploring the Performance of Ambient-based Policy Instruments when Nonpoint Source Polluters can Cooperate" American Journal of Agricultural Economics 86:1203-1210.

[39] Smith, R.B.W., and Y. Tsur. 1997. "Asymmetric Information and the Pricing of Natural Resources: The Case of Unmetered Water" Journal of Land Economics 73(3):394-403.

[40] Sanchez, I., and J. Sobel. 1993. "Hierarchical Design and Enforcement of Income Tax Policies" Journal of Public Economics 50:345-369.

[41] Seabright, P. 1997. "Is Cooperation Habit-Forming?", in P. Dasgupta \& K-G Mäler (eds): The Environment and Emerging Development Issues, Oxford: Clarendon Press.

[42] Segerson, K. 1988. "Uncertainty and Incentives for Nonpoint Pollution Control" Journal for Environmental Economics and Management 15(1):87-98.

[43] Spraggon, J. 2004. "Testing Ambient Pollution Instruments with Heterogenous Agents" Journal of Environmental Economics and Management 48:837-856.

[44] Stiglitz, J.E. 1990. "Peer Monitoring and Credit Markets" The World Bank Economic Review $4(3): 351-366$.

[45] Suter, J.F., C.A. Vossler, G.L. Poe, and K. Segerson. 2008. "Experiments on Damage-based Ambient Taxes for Nonpoint Source Polluters" American Journal of Agricultural Economics 90:86-102. 
[46] Tsur, Y. 2000. "Water Regulation via Pricing: The Role of Implementation Costs and Asymmetric Information" In A. Dinar, ed. The Political Economy of Water Pricing Reforms, Oxford University Press, Oxford.

[47] Vossler, C.A., G.L. Poe, W.D. Schulze, and K. Segerson. 2006. "Communication and incentive mechanisms based on group performance: an experimental study of nonpoint source pollution control" Economic Inquiry 44:599-613.

[48] Wade, R. 1987. "The Management of Common Property Resources: Collective Action as an Alternative to Privatization or State Regulation" Cambridge Journal of Economics 11:95-106.

[49] Wydick, B. 1999. "Can Social Cohesion be Harnessed to Repair Market Failures? Evidence from Group Lending in Guatemala," The Economic Journal 109(1457):463-475.

[50] Xepapadeas, A.P. 1991. "Environmental Policy under Imperfect Information: Incentives and Moral Hazard" Journal of Environmental Economics and Management 20:113-126.

[51] Xepapadeas, A.P. 1992. "Environmental Policy Design and Dynamic Non-point Source Pollution" Journal of Environmental Economics and Management 23:22-39.

[52] Hansen, L.G. 1998. "A damage Based Tax Mechanism for Regulation of Nonpoint Emissions" Environmental Resource Economics 12:99-112. 
Table 1. Summary of Descriptive Statistics

\begin{tabular}{lllllll}
\hline \hline Variable & Unit of measure & Obs & Mean & Std. Dev. & Min & Max \\
AGE & Year & 137 & 48.38 & 6.49 & 35 & 65 \\
ADVERSE CLIMATE & Index & 137 & 1.088 & 0.59 & 0 & 2 \\
ALTERNATIVE SOURCE & Percentage & 137 & 0.116 & 0.19 & 0 & 1 \\
ALTERNATIVE REVENUE & Binary variable & 137 & 0.255 & 0.438 & 0 & 1 \\
DENSITY & Individuals per hectare & 137 & 0.26 & 0.118 & 0.12 & 0.56 \\
DISTANCE & Kilometer & 137 & 1.4 & 0.815 & 0 & 3 \\
DISTANCE TO LARGE CITY & Kilometer & 137 & 15.43 & 5 & 7 & 25 \\
DRIP & Percentage & 137 & 0.3 & 0.13 & 0.1 & 0.6 \\
EDUCATION & Year & 137 & 5.63 & 1.93 & 3 & 10.33 \\
EQUIPPED SURFACE (ES) & Hectare & 137 & 234.2 & 172.34 & 20 & 706 \\
HILLYAREA & Percentage & 137 & 0.0572 & 0.0463 & 0 & 0.18 \\
PREVIOUS SPRINKLER & Percentage & 137 & 0.23 & 0.06 & 0.1 & 0.34 \\
PRICE & Tunisian Dinar per m 3 & & & & \\
& of water reported & 137 & 0.1033 & 0.027 & 0.05 & 0.14 \\
PUNISHMENT RATE (PR) & Days (for which farmers & & & & & \\
& are denied access to water & & & & & \\
RAINFALL & feeding the cooperative) & 137 & 26.25 & 9.36 & 12 & 42 \\
RED SOILS & per 10.000 m ${ }^{3}$ of water & & & & & \\
REVENUE SHOCK & stolen in the cooperative & & & & & \\
SIZE & Index & 137 & 0.956 & 0.77 & 0 & 2 \\
WATER SOURCE & Percentage & 137 & 0.2 & 0.127 & 0 & 0.7 \\
WATER THEFT & Index & 137 & 0.073 & 0.863 & -2 & 1 \\
YEAR & Farmer & 137 & 43.07 & 39.1 & 3 & 251 \\
CODE & Index & 137 & 1.85 & 1.37 & 0 & 4 \\
log(EQUIPPED SURFACE) & Percentage & 137 & 0.376 & 0.19 & 0 & 0.876 \\
log(SIZE) & Year & 137 & 2 & 0.804 & 1 & 3 \\
\hline \hline
\end{tabular}


Table 2. Determinants of WATER THEFT - Ordinary Least Squares

\begin{tabular}{|c|c|c|c|}
\hline Independent variable & $\begin{array}{c}\text { First OLS } \\
\text { specification }\end{array}$ & $\begin{array}{l}\text { Second OLS } \\
\text { specification }\end{array}$ & $\begin{array}{c}\text { With Cooperative } \\
\text { Fixed effects }\end{array}$ \\
\hline$A G E$ & $\begin{array}{c}0.0047 \\
(0.0015)^{* * *}\end{array}$ & $\begin{array}{l}0.0044 \\
(0.0016)^{* * *}\end{array}$ & $\begin{array}{l}-0.029 \\
(0.0076)^{* * *}\end{array}$ \\
\hline$D E N S I T Y$ & - & $\begin{array}{l}0.138 \\
(0.14)\end{array}$ & - \\
\hline DISTANCE & $\begin{array}{c}0.084 \\
(0.0156)^{* * *}\end{array}$ & $\begin{array}{c}0.077 \\
(0.0174)^{* * *}\end{array}$ & $\begin{array}{l}0.032 \\
(0.076)\end{array}$ \\
\hline$D R I P$ & -0.384 & $\begin{array}{l}-0.379 \\
(0.1024)^{* * *}\end{array}$ & $\begin{array}{l}-1.626 \\
(0.1853)^{* * *}\end{array}$ \\
\hline $\log (E S)$ & $\begin{array}{l}-0.071 \\
(0.0177)^{* * *}\end{array}$ & $\frac{-0.077}{(0.018)^{* * *}}$ & $\begin{array}{l}-0.069 \\
(0.46)\end{array}$ \\
\hline $\log (S I Z E)$ & $\begin{array}{c}0.124 \\
(0.0125)^{* * *}\end{array}$ & $\begin{array}{c}0.118 \\
(0.0135)^{* * *}\end{array}$ & $\begin{array}{c}0.124 \\
(0.0342)^{* * *}\end{array}$ \\
\hline PRICE & $\begin{array}{l}1.029 \\
(0.452)^{* *}\end{array}$ & $\begin{array}{l}1.107 \\
(0.486)^{* *}\end{array}$ & $\begin{array}{l}1.35 \\
(1.492)\end{array}$ \\
\hline PUNISHMENT RATE (PR) & $\frac{-0.0031}{(0.001)^{* * *}}$ & $\begin{array}{l}-0.0029 \\
(0.001)^{* * *}\end{array}$ & $\begin{array}{l}0.0116 \\
(0.0057)^{* *}\end{array}$ \\
\hline REVENUE SHOCK & $\frac{-0.034}{(0.0114)^{* * *}}$ & $\begin{array}{l}-0.033 \\
(0.0112)^{* * *}\end{array}$ & $\begin{array}{c}0.0038 \\
(0.015)\end{array}$ \\
\hline CONSTANT & $\begin{array}{l}0.068 \\
(0.0912)\end{array}$ & $\begin{array}{l}0.096 \\
(0.098)\end{array}$ & $\begin{array}{l}1.715 \\
(2.39)\end{array}$ \\
\hline $\mathrm{R}^{2}$ & 0.741 & 0.743 & 0.01 \\
\hline
\end{tabular}

Note: Robust standard errors (for the OLS specification) and standard errors (for the fixed effects specification) are in parentheses; $* * *$, and *** denote variables significant at $10 \%, 5 \%$, and $1 \%$ respectively.

1: $\mathrm{R}^{2}$ between is reported for the fixed effects specification. 
Table 3. Determinants of WATER THEFT - Instrumental Variables

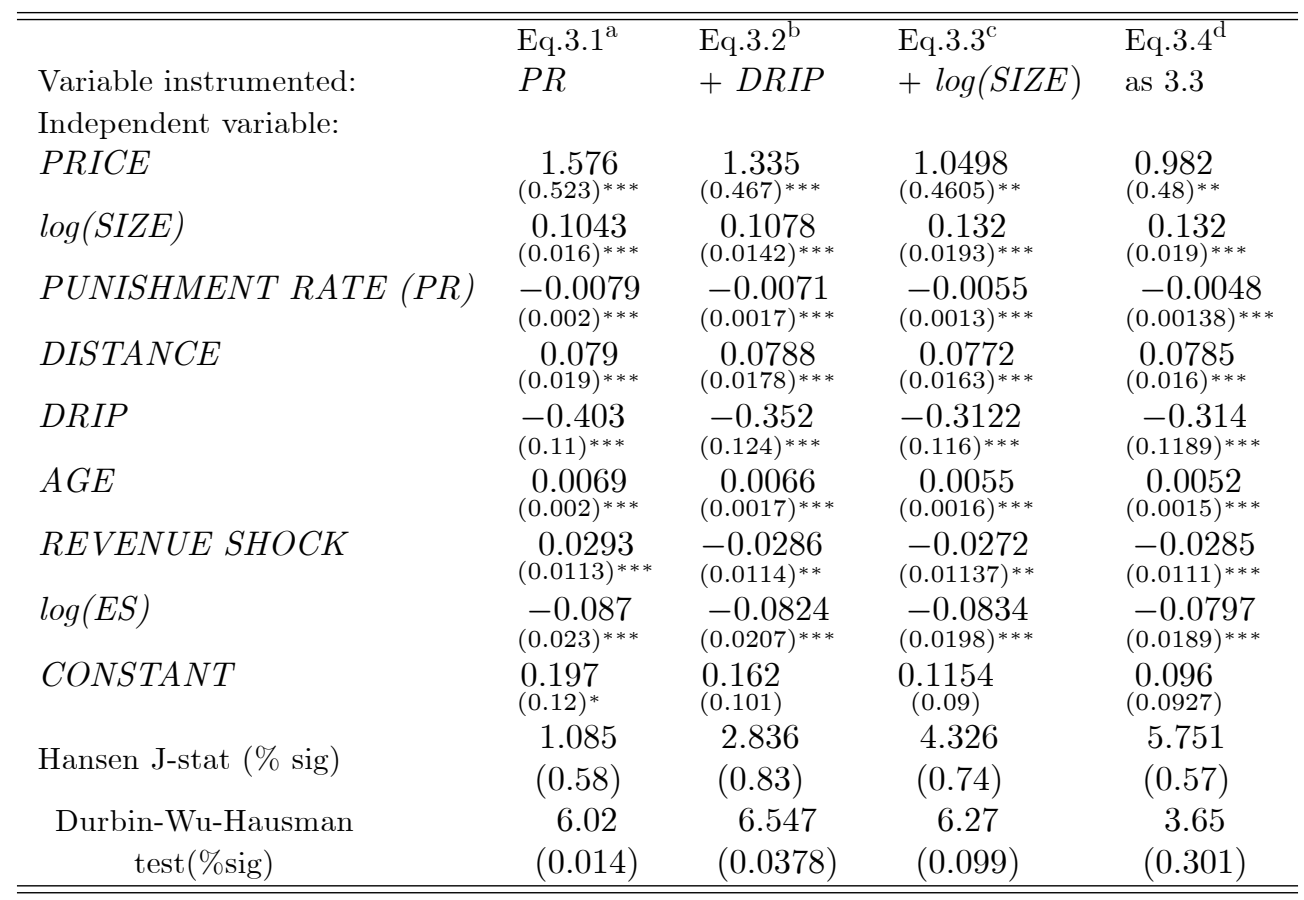

Note: Robust standard errors are in parentheses, clustered on cooperatives; *, **, and *** denote variables significant at $10 \%, 5 \%$, and $1 \%$ respectively.

a: The excluded instruments are education ${ }^{26}$, density, water source.

b: The excluded instruments are as in 3.1 plus red soils, rainfall, adverse climate, previous sprinkler, alternative revenue.

c: The excluded instruments are as in 3.2 plus hilly area and alternative source.

d: the excluded instruments are as in 3.3 minus education plus distance to large city. 
Tables 3.b, 3.c and 3.d below report the first-stage IV estimates of the instrumented variables in the estimation of WATER THEFT. First, in table 3.b, Equation 3.1 reports the estimates of PUNISHMENT RATE (PR), and Equation 3.2 reports the estimates of PR and DRIP. Second, in table 3.c, Equation 3.3 reports the estimates of PR, DRIP and $\log (\mathrm{SIZE})$. Finally, in table 3.d, Equation 3.4 reports the estimates of the same instrumented variables as in equation 3.3 (table 3.c), except that in the set of excluded instruments we replace EDUCATION by DISTANCE TO LARGE CITY. 
Table 3.b. First-Stage IV Estimates of the Instrumented Variables

in the Estimation of WATER THEFT (Eq.3.1 and Eq.3.2)

\begin{tabular}{|c|c|c|c|}
\hline & Eq.3.1 & Eq.3.2 & \\
\hline Instrumented variable & $P R$ & $P R$ & $D R I P$ \\
\hline \multicolumn{4}{|l|}{ Independent variable } \\
\hline PRICE & $\begin{array}{l}49.45 \\
(38.23)\end{array}$ & $\begin{array}{c}74.28 \\
(40.352)^{*}\end{array}$ & $\begin{array}{l}1.043 \\
(0.448)^{* *}\end{array}$ \\
\hline $\log (S I Z E)$ & $\begin{array}{c}-0.333 \\
(1.967)\end{array}$ & $\begin{array}{c}0.0832 \\
(1.79)\end{array}$ & 0.0034 \\
\hline PUNISHMENT RATE (PR) & - & - & - \\
\hline$D R I P$ & $\begin{array}{l}-6.87 \\
(7.87)\end{array}$ & - & - \\
\hline DISTANCE & $\begin{array}{l}0.07 \\
(2.15)\end{array}$ & $\underset{(1.912)}{-0.412}$ & $\begin{array}{c}-0.0152 \\
(0.018)\end{array}$ \\
\hline$A G E$ & $\begin{array}{c}0.473 \\
(0.179)^{* *}\end{array}$ & $\begin{array}{c}0.497 \\
(0.1794)^{* * *}\end{array}$ & $\begin{array}{c}-0.0002 \\
(0.0012)\end{array}$ \\
\hline REVENUE SHOCK & $\begin{array}{l}0.673 \\
(0.77)\end{array}$ & $\begin{array}{l}0.617 \\
(0.823)\end{array}$ & $\begin{array}{l}0.00313 \\
(0.0068)\end{array}$ \\
\hline $\log (E S)$ & $\begin{array}{c}-3.235 \\
(1.97)\end{array}$ & $\begin{array}{l}-3.42 \\
(1.86)^{*}\end{array}$ & $\begin{array}{c}-0.0143 \\
(0.0175)\end{array}$ \\
\hline EDUCATION & $\frac{2.13}{(0.63)^{* * *}}$ & $\begin{array}{l}2.198 \\
(0.59)^{* * *}\end{array}$ & $\begin{array}{l}0.00446 \\
(0.00325)\end{array}$ \\
\hline DISTANCE TO LARGE CITY & - & - & - \\
\hline DENSITY & $\begin{array}{l}-40.4 \\
(13.78)^{* *}\end{array}$ & $\begin{array}{l}-31.217 \\
(13.25)^{* *}\end{array}$ & $\begin{array}{c}-0.084 \\
(0.15)\end{array}$ \\
\hline WATER SOURCE & $\begin{array}{l}2.84 \\
(1.352)^{* *}\end{array}$ & $\begin{array}{c}2.48 \\
(1.23)^{* *}\end{array}$ & $\begin{array}{l}0.009 \\
(0.013)\end{array}$ \\
\hline$R E D S O I L S$ & - & $\begin{array}{l}3.98 \\
(9.28)\end{array}$ & $\begin{array}{c}0.23 \\
(0.0475)^{* * *}\end{array}$ \\
\hline ADVERSE CLIMATE & - & $\begin{array}{c}-0.059 \\
(1.79)\end{array}$ & $\begin{array}{c}0.066 \\
(0.018)^{* * *}\end{array}$ \\
\hline PREVIOUS SPRINKLER & - & $\begin{array}{l}14.87 \\
(14.89)\end{array}$ & $\begin{array}{l}0.709 \\
(0.173)^{* * *}\end{array}$ \\
\hline ALTERNATIVE REVENUE & - & $\begin{array}{l}-6.48 \\
(2.43)^{* * * *}\end{array}$ & $\begin{array}{l}0.0445 \\
(0.023)^{*}\end{array}$ \\
\hline RAINFALL & - & $\begin{array}{c}-0.535 \\
(0.675)\end{array}$ & $\begin{array}{c}-0.024 \\
(0.0086)^{* * *}\end{array}$ \\
\hline HILLY AREA & - & - & - \\
\hline ALTERNATIVE SOURCE & - & - & - \\
\hline CONSTANT & $\begin{array}{l}11.53 \\
(12.95)\end{array}$ & $\begin{array}{c}1.79 \\
(12.82)\end{array}$ & $\begin{array}{c}-0.0045 \\
(0.0734)\end{array}$ \\
\hline F-statistic (excluded instruments) & $F(3,48)=6.58$ & $F(8,48)=3.11$ & $F(8,48)=26.61$ \\
\hline
\end{tabular}


Table 3.c. First-Stage IV Estimates of the Instrumented Variables

in the Estimation of WATER THEFT (Eq.3.3)

\begin{tabular}{|c|c|c|c|}
\hline \multirow{3}{*}{$\begin{array}{l}\text { Instrumented variable } \\
\text { Independent variable }\end{array}$} & \multicolumn{3}{|l|}{ Eq.3.3 } \\
\hline & $P R$ & $D R I P$ & $\log (S I Z E)$ \\
\hline & & & \\
\hline PRICE & $\begin{array}{l}69.765 \\
(42.55)\end{array}$ & $\begin{array}{l}1.027 \\
(0.43)^{* *}\end{array}$ & $\begin{array}{l}2.976 \\
(2.615)\end{array}$ \\
\hline $\log (S I Z E)$ & - & - & - \\
\hline PUNISHMENT RATE (PR) & - & - & - \\
\hline DRIP & - & - & - \\
\hline DISTANCE & $\begin{array}{l}-0.36 \\
(1.74)\end{array}$ & $\begin{array}{c}-0.016 \\
(0.02)\end{array}$ & $\begin{array}{c}-0.072 \\
(0.087)\end{array}$ \\
\hline$A G E$ & $\begin{array}{l}0.501 \\
(0.188)^{* *}\end{array}$ & $\begin{array}{l}0.0005 \\
(0.0015)\end{array}$ & $\begin{array}{l}0.0007 \\
(0.0089)\end{array}$ \\
\hline REVENUE SHOCK & $\begin{array}{l}1.005 \\
(0.853)\end{array}$ & $\begin{array}{l}0.0002 \\
(0.0068)\end{array}$ & $\begin{array}{l}-0.055 \\
(0.093)\end{array}$ \\
\hline $\log E S$ & $\begin{array}{l}-3.36 \\
(1.77)^{*}\end{array}$ & $\begin{array}{c}-0.0104 \\
(0.0175)\end{array}$ & $\begin{array}{l}0.974 \\
(0.108)\end{array}$ \\
\hline EDUCATION & $\begin{array}{c}2.373 \\
(0.46)^{* * *}\end{array}$ & $\begin{array}{l}0.003 \\
(0.003)\end{array}$ & $\begin{array}{l}-0.092 \\
(0.036)^{* * *}\end{array}$ \\
\hline DISTANCE TO LARGE CITY & - & - & - \\
\hline DENSITY & $\begin{array}{c}-37.78 \\
(12.64)^{* * *}\end{array}$ & $\begin{array}{l}0.006 \\
(0.14)\end{array}$ & $\begin{array}{c}1.82 \\
(0.86)^{* *}\end{array}$ \\
\hline WATER SOURCE & $\begin{array}{c}2.803 \\
(1.236)^{* *}\end{array}$ & $\begin{array}{l}0.0049 \\
(0.0133)\end{array}$ & $\begin{array}{l}0.109 \\
(0.076)\end{array}$ \\
\hline$R E D S O I L S$ & $\begin{array}{l}6.29 \\
(8.74)\end{array}$ & $\begin{array}{c}0.212 \\
(0.045)^{* * *}\end{array}$ & $\begin{array}{l}0.108 \\
(0.46)\end{array}$ \\
\hline ADVERSE CLIMATE & $\begin{array}{l}0.32 \\
(1.69)\end{array}$ & $\begin{array}{c}0.058 \\
(0.0164)^{* * *}\end{array}$ & $\begin{array}{l}-0.082 \\
(0.0906)\end{array}$ \\
\hline PREVIOUS SPRINKLER & $\begin{array}{l}17.71 \\
(14.24)\end{array}$ & $\begin{array}{l}0.697 \\
(0.168)^{* * *}\end{array}$ & $\begin{array}{l}0.77 \\
(0.53)\end{array}$ \\
\hline ALTERNATIVE REVENUE & $\begin{array}{l}-6.02 \\
(2.32)^{* *}\end{array}$ & $\begin{array}{l}0.042 \\
(0.02)^{*}\end{array}$ & $\begin{array}{c}0.23 \\
(0.104)\end{array}$ \\
\hline$R A I N F A L L$ & $\begin{array}{c}-0.42 \\
(0.66)\end{array}$ & $\begin{array}{c}-0.025 \\
(0.0085)^{* *}\end{array}$ & $\begin{array}{c}-0.005 \\
(0.029)\end{array}$ \\
\hline$H I L L Y A R E A$ & $\begin{array}{c}-14.745 \\
(22.004)\end{array}$ & $\begin{array}{l}0.313 \\
(0.22)\end{array}$ & $\begin{array}{l}-4.08 \\
(1.81)^{* *}\end{array}$ \\
\hline ALTERNATIVE SOURCE & $\begin{array}{l}-8.267 \\
(3.128)^{* *}\end{array}$ & $\begin{array}{c}0.044 \\
(0.0216)^{* *}\end{array}$ & $\begin{array}{l}-1.52 \\
(0.416)^{* * *}\end{array}$ \\
\hline CONSTANT & $\begin{array}{l}2.094 \\
(12.56)\end{array}$ & $\begin{array}{c}-0.055 \\
(0.093)\end{array}$ & $\begin{array}{c}2.76 \\
(0.655)^{* * *}\end{array}$ \\
\hline F-statistic (excluded instruments) & $F(10,48)=6.63$ & $F(10,48)=20.99$ & $F(10,48)=11.85$ \\
\hline
\end{tabular}


Table 3.d. First-Stage IV Estimates of the Instrumented Variables

in the Estimation of WATER THEFT (Eq.3.4)

\begin{tabular}{|c|c|c|c|}
\hline & \multicolumn{3}{|l|}{ Eq.3.4 } \\
\hline Instrumented variable & $P R$ & $D R I P$ & $\log (S I Z E)$ \\
\hline \multicolumn{4}{|l|}{ Independent variable } \\
\hline PRICE & $\begin{array}{c}150.18 \\
(49.003)^{* * *}\end{array}$ & $\begin{array}{c}0.97 \\
(0.47)^{* *}\end{array}$ & $\begin{array}{c}0.104 \\
(2.69)\end{array}$ \\
\hline $\log (S I Z E)$ & - & - & - \\
\hline PUNISHMENT RATE (PR) & - & - & - \\
\hline$D R I P$ & - & - & - \\
\hline DISTANCE & $\begin{array}{c}-2.78 \\
(1.84)\end{array}$ & $\begin{array}{l}-0.013 \\
(0.0175)\end{array}$ & $\begin{array}{c}0.0126 \\
(0.094)\end{array}$ \\
\hline$A G E$ & $\begin{array}{c}0.49 \\
(0.182)^{* * *}\end{array}$ & $\begin{array}{l}0.0005 \\
(0.0014)\end{array}$ & $\begin{array}{c}0.0013 \\
(0.009)\end{array}$ \\
\hline REVENUE SHOCK & $\begin{array}{l}0.94 \\
(0.88)\end{array}$ & $\begin{array}{c}0.0007 \\
(0.007)\end{array}$ & $\begin{array}{c}-0.044 \\
(0.036)\end{array}$ \\
\hline loges & $\begin{array}{c}-5.42 \\
(1.86)^{* * *}\end{array}$ & $\begin{array}{c}-0.0077 \\
(0.018)\end{array}$ & $\begin{array}{l}0.17 \\
(0.12)\end{array}$ \\
\hline EDUCATION & - & - & - \\
\hline DISTANCE TO LARGE CITY & $\begin{array}{c}-1.047 \\
(0.244)^{* * *}\end{array}$ & $\begin{array}{l}0.0014 \\
(0.0022)\end{array}$ & $\begin{array}{c}0.036 \\
(0.015)^{* *}\end{array}$ \\
\hline DENSITY & $\begin{array}{c}-25.1 \\
(14.42)^{*}\end{array}$ & $\begin{array}{c}-0.0144 \\
(0.144)\end{array}$ & $\begin{array}{l}1.39 \\
(0.89)\end{array}$ \\
\hline WATER SOURCE & $\begin{array}{c}3.65 \\
(1.27)^{* * *}\end{array}$ & $\begin{array}{c}0.00013 \\
(0.012)\end{array}$ & $\begin{array}{l}0.086 \\
(0.087)\end{array}$ \\
\hline$R E D S O I L S$ & $\begin{array}{l}11.47 \\
(7.69)\end{array}$ & $\begin{array}{c}0.19 \\
(0.04)^{* * *}\end{array}$ & $\begin{array}{c}-0.045 \\
(0.58)\end{array}$ \\
\hline ADVERSE CLIMATE & $\begin{array}{c}0.32 \\
(1.81)\end{array}$ & $\begin{array}{c}0.058 \\
(0.017)^{* * *}\end{array}$ & $\begin{array}{l}-0.08 \\
(0.097)\end{array}$ \\
\hline PREVIOUS SPRINKLER & $\begin{array}{l}19.72 \\
(15.92)\end{array}$ & $\begin{array}{c}0.71 \\
(0.17)^{* * *}\end{array}$ & $\begin{array}{l}0.68 \\
(0.55)\end{array}$ \\
\hline ALTERNATIVE REVENUE & $\begin{array}{c}-5.48 \\
(2.62)^{* *}\end{array}$ & $\begin{array}{l}0.042 \\
(0.022)^{*}\end{array}$ & $\begin{array}{c}0.21 \\
(0.105)^{*}\end{array}$ \\
\hline$R A I N F A L L$ & $\begin{array}{c}-0.64 \\
(0.74)\end{array}$ & $\begin{array}{c}-0.025 \\
(0.0082)^{* * *}\end{array}$ & $\begin{array}{c}0.0029 \\
(0.032)\end{array}$ \\
\hline$H I L L Y A R E A$ & $\begin{array}{l}1.27 \\
(28.77)\end{array}$ & $\begin{array}{l}0.042 \\
(0.022)^{*}\end{array}$ & $\begin{array}{c}-4.66 \\
(1.72)^{* * *}\end{array}$ \\
\hline ALTERNATIVE SOURCE & $\begin{array}{c}-9.52 \\
(3.34)^{* * *}\end{array}$ & $\begin{array}{c}0.055 \\
(0.026)^{* *}\end{array}$ & $\begin{array}{c}-1.49 \\
(0.43)^{* * *}\end{array}$ \\
\hline CONSTANT & $\begin{array}{c}30.92 \\
(14.56)^{* *}\end{array}$ & $\begin{array}{c}-0.057 \\
(0.09)\end{array}$ & $\begin{array}{l}1.705 \\
(0.76)^{* *}\end{array}$ \\
\hline F-statistic (excluded instruments) & $F(10,48)=4.43$ & $F(10,48)=24.10$ & $F(10,48)=12.80$ \\
\hline
\end{tabular}


Table 4. Determinants of PUNISHMENT RATE

\begin{tabular}{llll}
\hline \hline Independent variable & Eq.4.1 & Eq.4.2 & Eq.4.3 \\
Specification & OLS & OLS & 2 SLS \\
AGE & 0.457 & 0.438 & 0.452 \\
DENSITY & $(0.1502)^{* * *}$ & $(0.167)^{* *}$ & $(0.149)^{* * *}$ \\
& -55.07 & -53.965 & -56.098 \\
DISTANCE & $(9.926)^{* * *}$ & $(10.73)^{* * *}$ & $(10.254)^{* * *}$ \\
& - & -0.525 & - \\
EDUCATION & & $(1.965)$ & \\
WATER SOURCE & 2.195 & 2.197 & 1.928 \\
CONSTANT & $(0.599)^{* * *}$ & $(0.607)^{* * *}$ & $(0.806)^{* *}$ \\
$\mathrm{R}^{2}$ & 2.662 & 2.837 & 2.561 \\
Durbin-Wu-Hausman test(\%sig) & $-(1.072)^{* *}$ & $(1.22)^{* * *}$ & $(1.056)^{* *}$ \\
\hline \hline & 1.303 & 2.33 & 3.511 \\
& $0.36)$ & $(9.545)$ & $(9.786)$ \\
\hline
\end{tabular}

Note: Robust standard errors are in parentheses, clustered on cooperatives; ${ }^{*},{ }^{* *}$, and $* * *$ denote variables significant at $10 \%, 5 \%$, and $1 \%$ respectively. 


\section{Table 5. Determinants of $\log (S I Z E)$}

\begin{tabular}{llll}
\hline \hline Independent variable & Eq.5.1 & Eq.5.2 & Eq.5.3 \\
Specification & OLS & OLS & 2 SLS \\
ALTERNATIVE SOURCE & -1.413 & -1.415 & -1.343 \\
& $(0.37)^{* * *}$ & $(0.369)^{* * *}$ & $(0.41)^{* * *}$ \\
DENSITY & 1.762 & 1.835 & 1.69 \\
& $(0.76)^{* *}$ & $(0.61)^{* * *}$ & $(0.798)^{* * *}$ \\
DISTANCE & 0.023 & - & 0.0232 \\
EDUCATION & $(0.926)$ & & $(0.094)$ \\
HILLY AREA & -0.0874 & -0.08742 & -0.136 \\
WATER SOURCE & $(0.042)^{* * *}$ & $(0.0418)^{* * *}$ & $(0.045)^{* * *}$ \\
CONSTANT & -3.854 & -3.761 & -3.597 \\
$\mathrm{R}^{2}$ & $(1.83)^{* *}$ & $(1.69)^{* * *}$ & $(1.947)^{*}$ \\
Durbin-Wu-Hausman test (\%sig) & 0.185 & 0.190 & 0.161 \\
\hline \hline
\end{tabular}

Note: Robust standard errors are given in parentheses, clustered on cooperatives; *, **, and *** denote

variables significant at $10 \%, 5 \%$, and $1 \%$ respectively. 
Table 4.b reports the first-stage IV estimates of the instrumented variables in the estimation of PUNISHMENT RATE and $\log (\mathrm{SIZE})$. In Equations $4.3(\mathrm{PR})$ and $5.2(\log (\mathrm{SIZE}))$, we report the estimates of EDUCATION.

Table 4.b. First-Stage IV Estimates of the Instrumented Variables

in the Estimation of PUNISHMENT RATE (PR) and $\log (\boldsymbol{S I Z E})$

\begin{tabular}{lll}
\hline \hline & Eq.4.3 $(P R)$ & Eq.5.2 $(\log (S I Z E))$ \\
Instrumented variable & EDUCATION & EDUCATION \\
Independent variable & -0.3076 & 0.466 \\
DISTANCE & $(0.37)$ & $(-0.416)$ \\
AGE & -0.021 & - \\
EDUCATION & $(0.033)$ & - \\
DISTANCE TO LARGE CITY & - & -0.27 \\
DENSITY & $(0.042)^{* * *}$ & $(0.043)^{* * *}$ \\
WATER SOURCE & -4.454 & -0.766 \\
& $(1.93)^{* *}$ & $(3.39)$ \\
ALTERNATIVE SOURCE & 0.377 & 0.283 \\
HILLY AREA & $(0.27)$ & $(0.271)$ \\
CONSTANT & - & 0.35 \\
F-statistic (excluded instruments) & $F(1,48)=41.03$ & $(1.116)$ \\
\hline \hline
\end{tabular}

